\title{
Central bank FOREX interventions assessed using realized moments
}

Citation for published version (APA):

Beine, M., Laurent, S., \& Palm, F. C. (2003). Central bank FOREX interventions assessed using realized moments. METEOR, Maastricht University School of Business and Economics. METEOR Research Memorandum No. 043 https://doi.org/10.26481/umamet.2003043

Document status and date:

Published: 01/01/2003

DOI:

10.26481/umamet.2003043

Document Version:

Publisher's PDF, also known as Version of record

\section{Please check the document version of this publication:}

- A submitted manuscript is the version of the article upon submission and before peer-review. There can be important differences between the submitted version and the official published version of record.

People interested in the research are advised to contact the author for the final version of the publication, or visit the DOI to the publisher's website.

- The final author version and the galley proof are versions of the publication after peer review.

- The final published version features the final layout of the paper including the volume, issue and page numbers.

Link to publication

\footnotetext{
General rights rights.

- You may freely distribute the URL identifying the publication in the public portal. please follow below link for the End User Agreement:

www.umlib.nl/taverne-license

Take down policy

If you believe that this document breaches copyright please contact us at:

repository@maastrichtuniversity.nl

providing details and we will investigate your claim.
}

Copyright and moral rights for the publications made accessible in the public portal are retained by the authors and/or other copyright owners and it is a condition of accessing publications that users recognise and abide by the legal requirements associated with these

- Users may download and print one copy of any publication from the public portal for the purpose of private study or research.

- You may not further distribute the material or use it for any profit-making activity or commercial gain

If the publication is distributed under the terms of Article $25 \mathrm{fa}$ of the Dutch Copyright Act, indicated by the "Taverne" license above, 


\title{
CENTRAL BANK FOREX INTERVENTIONS ASSESSED USING REALIZED MOMENTS*
}

\author{
Michel BEINE† Sébastien LAURENT ${ }^{\ddagger}$ and Franz C. PALM ${ }^{\S}$
}

November, 4, 2003

\begin{abstract}
This paper studies and assesses the impact of G3 Central Bank interventions on the DEM/USD exchange rate properties using daily realized moments of exchange rate returns (obtained from intraday data) for the period 1989-2001. Event studies in terms of the realized moments for the intervention day, the days preceding and following the intervention day illustrate the shape of this impact. Rolling regressions results for an ARFIMA model for realized moments are used to measure the intervention impact and characterize its significance.

The analysis confirms previous findings of an increase of volatility after a coordinated Central Bank intervention. It highlights new findings on the timing and the persistence of coordinated interventions on exchange rate volatility, on important volatility spillovers, on the impact on exchange rate covariances and correlations and on skewness coefficients.

JEL Classifications: C22, E44, F31, G15.
\end{abstract}

Keywords: Central Bank Interventions, Exchange Rates Realized Moments, Intradaily Dynamics.

${ }^{*}$ We would like to thank Gust Janssens for providing the exchange rate data. This paper has benefitted from useful comments and suggestions from participants at seminars at the Erasmus University of Rotterdam, CRESTINSEE in Paris, the Bank of Canada, Ottawa, CORE, Louvain-la-Neuve, Belgium, at the University of Konstanz, and at Ente L. Einaudi, Rome, Italy and at the conference on realized volatility organized at the University of Montreal, Canada. We particular thank C. D'Souza, C. De Vries, C. Gourieroux, L. Lescourret, D. van Dijck and H. van Dijck. Of course, the usual disclaimer applies.

${ }^{\dagger}$ CADRE, University of Lille 2 (France) and Free University of Brussels (Belgium); mbeine@ulb.ac.be

${ }^{\ddagger}$ CREST (France) and CORE (Belgium); Sebastien.Laurent@ensae.fr

$\S$ Corresponding author: Maastricht University, Faculty of Economics and Business Administration, P.O.B. 616, 6200 MD Maastricht (The Netherlands), and fellow of CESifo; F.Palm@ke.unimaas.nl 


\section{Introduction}

In a period of thirteen years (1989-2001) central banks of the US, Japan and Germany(Europe) intervened about 430 times in either the DM-Dollar or the Yen-Dollar market. This means that on average almost three interventions occurred per month. It is perhaps not surprising to see central banks frequently intervening in markets that are of crucial importance for the international competitiveness. Given the importance of foreign exchange markets it is for scientific and policy reasons of interest to attempt to assess the impact Central Bank interventions have on exchange rates. This paper belongs to the growing literature using intraday information to study and assess the impact of Central Bank Interventions (CBI) on forex markets. Previous studies have used daily or weekly forex (FX) data to document level and variance effects of CBI's. Among the more recent literature using intraday data, Dominguez (2003) pays particular attention to the influence of intraday market conditions on effectiveness of the CBI's.

The objective of the paper is twofold. First, by conducting event studies of the periods preceding and following CBI's our aim is to document the various effects of CBI's, whether desired or not. Using daily realized moments (see a.o. Andersen, Bollerslev, Diebold and Labys 1999, 2001) obtained from hourly FX data on the DEM/USD rates for the period from January 4, 1989 to February 28, 2001, the paper analyzes the shape of the impact of CBI's on mean returns, volatility and other higher moments as well as on several spillover measures. Interestingly, under appropriate conditions, daily realized moments yield consistent and highly efficient estimates of return moments and superior forecasts (see e.g. Andersen, Bollerslev, Diebold and Labys, 2003, on realized volatility). Moreover they have the advantage to correct for specific hour-of-the-day effects. Using boxplots covering the intervention day, the two preceding days and the two days after we carry out an event study describing the pattern of the market reactions to interventions. ${ }^{1}$ We distinguish between unilateral interventions by the Bundesbank and the US Federal Reserve respectively and coordinated interventions of these Central Banks on the DEM/USD rate. We also study the impact of spillovers on the DEM/USD rate of unilateral interventions of the Bank of Japan and the US Federal Reserve respectively and coordinated interventions of these Banks in the YEN/USD market. We also check the impact of sequences of interventions.

Second, the paper goes beyond describing the impact of CBI's. Using rolling regressions it attempts to explain movements in realized moments by relating these moments to the type of intervention and to dummy variables for the day of the week. This analysis is carried out to measure sign, size and significance of the various types of interventions. Thereby, we hope to measure the most important effects of CBI's on the exchange rate distribution. The boxplots exhibit differences in the impact of CBI 's between high and low volatility regimes. This analysis could be extended further by accounting for other states of the market variables at the time of the intervention (see e.g. Dominguez (2003) who finds that when trading volume is large or when a macroeconomic announcement has been scheduled interventions are expected to have big effects). Another possible extension could consist of a joint analysis of realized moments. These two extensions are left for future work.

While our analysis resembles that of Dominguez (2003) in some respects, there are important

\footnotetext{
${ }^{1}$ Throughout the rest of the paper, we will use the term "boxplot" to refer to the graphs reporting the evolution over time of the quartiles of the exchange rate moments. While the term might not be strictly appropriate, we follow the practice of the literature.
} 
differences. We prefer to use less noisy and more efficient realized moment measures up to order three for the period 1989-2001 instead of relying on returns and squared returns as Dominguez does to assess the impact of CBI's on the mean and volatility of exchange rates for the period 1987-1995. We also find CBI 's to affect higher moments and to have significant spillover effects from other foreign exchange markets.

The paper is organized as follows. In Section 2, we shall report boxplots of various realized moments for the different types of interventions mentioned above, starting two days before the day when the intervention occurred and including realized moments up to the end of the second day after the intervention. After this visual and model free inspection, rolling regressions (rolled over the various hours of the day) are estimated on the realized moments to quantify (and test) the impact of CBI's across hours of the day. In Section 3 we shall discuss the modelling implications of our empirical findings. Section 4 draws some general lessons both for modelling and for policy interventions from our analysis.

\section{The Impact of CBI's on Daily Realized FX Moments}

\subsection{Introduction}

As they convey a large piece of information about fundamentals and future monetary policies (see Mussa 1981), direct sterilized CBI's in the FX markets are expected to exert important effects on exchange rate dynamics. ${ }^{2}$ While the core of the empirical literature devoted to studying the impact of CBI's focused mostly on returns and volatility (see for recent surveys Baillie et al. 2000 and Sarno and Taylor 2001), the CBI's may have other possibly unintended side-effects on exchange rates. As we will show, the effects also highly depend on the type of CBI. Possibly, they also differ depending on the state of the market when the intervention takes place, as has been shown by Dominguez (2003) for returns and by Beine, Laurent and Lecourt (2003) concerning volatility. However accounting for different states of the market will be left for future research.

For two major exchange rates (DEM/USD and YEN/USD), we distinguish between six different types of official interventions: ${ }^{3}$

1. unilateral interventions conducted by the Bundesbank (ECB after 1999) on the DEM/USD market denoted BBU,

2. unilateral interventions by the US Federal Reserve on the DEM/USD market denoted FEDU,

3. coordinated interventions defined as interventions conducted on the DEM/USD market the same day and in the same direction by the two involved central banks denoted COORD,

4. unilateral interventions conducted by the Bank of Japan (BoJ) on the YEN/USD market denoted BoJU,

\footnotetext{
${ }^{2}$ The central bank interventions considered here are obviously sterilized. This rules out any scope for the so-called monetary channel.

${ }^{3}$ In this paper, we focus on official interventions and do not make any distinction between secret and reported interventions (see Dominguez and Frankel 1993 as well as Dominguez 1998). While interesting, the so-called secret puzzle (Sarno and Taylor 2001) mostly applies to the eighties. Since the beginning of the nineties, most major central banks have increased the transparency of their FX operations. This evolution is obvious for the Fed but also for the BoJ (see Ito 2002 on this point). Central Bank customer transactions resulting from the request for foreign currency by the government are excluded from CBI 's.
} 
5. unilateral interventions by the US Federal Reserve on the YEN/USD market denoted FEDUY,

6. coordinated interventions defined as interventions conducted on the YEN/USD market the same day and in the same direction by the two involved central banks denoted COORDY. ${ }^{4}$

Note that sometimes we make the distinction between CBI's involving purchases or sales of USD. For instance, unilateral purchases (resp. sales) of the Bundesbank are denoted by BBUp (resp. BBUs).

Similarly, we study six potential effects:

1. effects in terms of exchange rate returns,

2. effects in terms of exchange rate volatility on the market on which the CBI takes place,

3. volatility spillover, i.e. effects on the volatility of a CBI in another market,

4. effects on the covariance between exchange rates,

5. effects on the correlation between exchange rates,

6. and effects on higher moments of exchange rates, namely skewness. ${ }^{5}$

In the following subsections, we report for each case a summary of the main findings of the literature. A major contribution of this paper is to provide new evidence of the impact of CBI's on realized moments of intradaily hourly exchange rate returns during the two days preceding an intervention, the intervention day itself and the two days after the intervention occurred. This allows to highlight several important findings in terms of CBI impacts, namely impact persistence and the importance of choosing the appropriate quotation time.

\subsection{Intradaily approaches}

The use of intradaily data has been found to yield interesting insights on the impact of central bank interventions, as documented for instance by Dominguez (2003). Actually, Dominguez (2003) relies on news reports provided by the wire services to capture the exact timing of the interventions. Chang and Taylor (1998) followed the same strategy to capture intraday effects of CBI in the YEN/USD markets. By contrast, no official release of the exact timing of the intervention operation is available. ${ }^{6}$ Therefore, one has to rely on reported rather than official interventions to assess the efficiency of FX operations conducted by the central banks. Nevertheless, there might be some discrepancy between both types of interventions. First, by using reported interventions rather than official interventions one neglects the so-called secret interventions, i.e. official interventions that are unknown to dealers in the FX markets. ${ }^{7}$ While the bulk of secret interventions took place mostly in the eighties, a significant number of CBIs conducted by the BoJ in the early nineties remained secret. Our investigation period ranging from 1989 to 2001 obviously includes

\footnotetext{
${ }^{4}$ We neglect Bundesbank and BoJ interventions on the DEM/YEN market as they were very rare.

${ }^{5}$ For the sake of comparison with previous findings (Galati and Melick, 1999), we focus only on skewness and do not consider kurtosis. Such an investigation is left for future work.

${ }^{6}$ One exception concerns the CBI's carried out by the Swiss National Bank. See Payne and Vitale (2003).

${ }^{7}$ Dominguez (2003) mentions that over the 1989-1995 period, $25 \%$ of the Fed interventions were not reported by Reuters.
} 
some secret interventions, which calls for an alternative approach to the use of intradaily data. Second, there might be a significant lag between the effective operation(s) and the reporting of central bank interventions. ${ }^{8}$ Importantly, the lengths of these lags may be variable as the reporting depends on the dealers willingness to release the information.

Another reason why conducting a purely intraday analysis may be cumbersome is that intraday FX data are known to exhibit a complex seasonality. This intraday periodicity gives rise to a striking repetitive (U-shape) pattern in the autocorrelations of the absolute returns (proxy for the volatility). In this respect, Andersen and Bollerslev (1997) have shown that neglecting this seasonality pattern leads to obvious misspecification biases and thus to misleading economic interpretations. One way to deal with this issue is to use a seasonal filter. ${ }^{9}$ Nevertheless, as the CBI's occur at regular time during business hours (as we will document from our subsequent estimations), the filtering procedure may remove much of the effect of these interventions. As an alternative, one can fully specify the seasonal dynamics in the specification as illustrated by Andersen and Bollerslev (1998). Nevertheless, relying on a standard intraday approach to fully characterize the impact of CBI's on the first four moments would lead to a complicated and hardly manageable model. Using intraday realized moments computed over a 24-hour period as we propose in this paper avoids having to worry about the intraday seasonality pattern (see below).

\subsection{Effects on Daily Returns}

Basically, intervention policies may be prompted by different objectives. ${ }^{10}$ Amongst these objectives, influencing trend movements in the level of exchange rate returns is obviously the most frequent one. It has been basically the objective of the Fed, the Bundesbank and the BoJ since the late seventies, with an important exception after the Louvre Agreement in February 1987 until the beginning of the nineties. One obvious recent example of a central bank aiming at reversing undesirable trends in exchange rates is provided by the very active intervention policy followed by the BoJ. As suggested by Ito (2002), interventions leading to a weaker yen belong to the set of policy measures aiming at improving the recent Japanese economic and financial situation.

Unilateral interventions aiming at influencing exchange rate returns have been used by the three major central banks. Nevertheless, as illustrated by the Plaza Agreement in September 1985 that promotes central bank cooperation in order to depreciate the dollar, coordinated interventions are considered as more effective for influencing the level of exchange rates (Catte et al. 1992). On the whole, the empirical literature provides very weak evidence on systematic impacts of central bank interventions on exchange rate returns at a daily frequency. In general, authors do not identify any robust effect in the conditional mean of exchange rate returns (Baillie and Osterberg 1997a). Nevertheless, Baillie and Osterberg (1997b) find some empirical support for interventions

\footnotetext{
${ }^{8}$ Such a presumption is confirmed by the recent results obtained by Payne and Vitale (2003). Using reported interventions of the Fed they find that exchange rates react up to 45 minutes ahead of Reuters intervention reports.

${ }^{9}$ Interestingly, Dominguez (1999) uses two methods in order to account for intraday seasonal patterns in exchange rate volatility. This makes the estimation of the impact of reported interventions quite cumbersome. One question in using this approach concerns the relationship between the observed seasonal patterns and the occurrence of news or interventions. Dominguez (2003) does not include seasonal filtering but compares intraday volatilities (captured by the squared 5-minutes returns) between episodes of interventions and days of non intervention and tests for the equality of the two variances. While straightforward, this procedure does not rely on regressions allowing to capture the effects in terms of volatility persistence.

${ }^{10}$ Focusing on the Fed policies, Dominguez (1999) reports four different aims: influencing trend movements in the level of exchange rates, calming disorderly markets (i.e. eliminating excess volatility), rebalancing the foreign exchange reserves and intervening in support of other central banks.
} 
influencing forward exchange risk premium. When some effects on the spot exchange rate returns are detected, the impact is contrary to the objectives, i.e. purchases of US dollar leading to a depreciation of the dollar (Baillie and Osterberg 1997a, Beine et al. 2002). This perverse result tends to hold for both unilateral and coordinated interventions. This result has usually been interpreted as a lack of credibility of central banks adopting a leaning-against-the wind policy. Quite recently however, focusing on the interventions conducted by the National Bank of Switzerland, Payne and Vitale (2003) find evidence of effective operations in the very short run (15 to 30 minutes).

Denote by $y_{t, \theta}$ the realized return of day $t$ quoted at hour $\theta(\theta=0,1, \ldots, 23)$. Using intraday exchange rate returns defined on an hourly basis (see Appendix 1 for details on data), $y_{t, \theta}$ can be computed as:

$$
y_{t, \theta}=\sum_{j=0}^{23} r_{t, \theta-j}
$$

in which $r_{t, j}$ denotes the intraday hourly return of the corresponding exchange rate peculiar to day $t$ between time $j-1$ and $j$ and by convention $r_{t,-j}=r_{t-1,24-j}$ for $j=1,2, \ldots, 23$.

An event study can be performed to assess the impact of the CBI's on this realized moment. For instance, in order to evaluate the effects of unilateral USD purchases by the Bundesbank, Panel 1 of Figure 1 plots the median (solid line) as well as the first and third quartiles (dashed lines) of the subsample of daily realized returns $y_{t, \theta}$ for each intervention day, the two preceding days and the two days after. Since we have no precise information about the timing of the official interventions, we vary $\theta$ between 0 and 23 to describe the pattern of the market reactions to interventions. This gives a set of 24 points on each figure (ranging from 0 to 1 on the graph for the intervention day), each tick corresponding to an increment of $\theta$ (starting at 0 each day). Furthermore, to give a more comprehensive overview of the impact of CBI's, the boxplots for the two days preceding (from -2 to 0 on the graphs) and following the intervention days (from 1 to 3 on the graphs) are provided as well. ${ }^{11}$

Figures 1 and 2 present respectively the boxplot corresponding to unilateral and coordinated interventions. On the whole, the evidence is consistent with the previous findings exhibiting a weak impact of CBI in terms of returns. ${ }^{12}$

Somewhat surprisingly, there is no or very little effect of unilateral purchases or sales on the median and the lower and upper quartiles of the returns during the intervention days. Coordinated interventions also have little impact on the median return during the intervention days. ${ }^{13}$

The interquartile ranges however sharply increase in the second part of the intervention day and remain large during part of the day following the intervention day. This latter effect is due to the moving average feature of realized intraday returns. Here again, we may conclude that while materializing quickly any effect of interventions is of a temporary nature too. The increase of the interquartile ranges is consistent with the finding documented in the literature that CIB's tend temporarily increase uncertainty in the FX market (Dominguez 1998). This finding will be

\footnotetext{
${ }^{11}$ We do not investigate here the presence of potential long run effects of interventions (such as J-shape effects), i.e. effects beyond 2 business days.

${ }^{12}$ Appendix 1 describes the sources of CBI data. These data are official intervention data. Table A1 in Appendix 1 reports the number of occurrences of each kind of intervention.

${ }^{13}$ The upper panel of Figure 1 suggests that coordinated USD sales induce a small depreciation of the USD. This impact is much less obvious for coordinated purchases. Given that we focus on hourly returns, these results are not inconsistent with those of Payne and Vitale (2003).
} 
confirmed when we study the impact of CBI's on volatity measures.

Insert Figures 1 and 2 about here.

\subsection{Effects on Daily Volatility}

Examples of explicit attempts to smooth exchange rate volatility through unilateral interventions are provided by the policy followed by the Bank of Canada before 1995 (see Murray et al. 1997). Indeed, the Bank of Canada adopted the rule of an automatic intervention when absolute daily changes of the CAD/USD exchange rate (often used in the past together with squared daily returns as a noisy proxy of the volatility) exceeded some threshold. The Louvre Agreement which was reached in February 1987 promoted central bank cooperation in order to counteract excess exchange rate volatility on the major FX markets. This agreement resulted in frequent coordinated intervention operations of the Bundesbank and the Fed between February 1987 and the end of 1990.

The literature provides some evidence that a CBI tends to increase exchange rate volatility. Furthermore, such a finding is robust to the measurement of exchange rate volatility: this holds for ex post volatility captured by univariate GARCH models (Baillie and Osterberg 1997a, Dominguez 1998, Beine et al. 2002) ${ }^{14}$; this is also the case when focusing on ex ante or expected volatility measured by implied volatilities extracted from currency option prices (Bonser-Neal and Tanner 1996, Dominguez 1998, Galati and Melick 1999).

Following recent work of Andersen et al. (2001), the daily volatility $\sigma_{t, \theta}^{2}$ of day $t$ observed at time $\theta$, is computed as the sum of the current and the 23 previous squared hourly returns: 15

$$
\sigma_{t, \theta}^{2}=\sum_{j=0}^{23} r_{t, \theta-j}^{2} .
$$

Unlike the daily squared returns that provide unbiased but very noisy volatility proxies, the daily realized volatility yields consistent and highly efficient estimates of the volatility (see Andersen et al. 2001 for more details about the properties of the realized volatility in a continuous time framework).

Insert Figure 3 about here.

As in Subsection 2.3, an event study visualizes the impact of the CBI's on the realized volatility. From the boxplots reported in Figure 3, one identifies an important increase of volatility (measured by $\sigma_{t, \theta}^{2}$ ) related to FX interventions. This result, which is fully consistent with the literature, obviously holds for coordinated interventions of the Fed and the Bundesbank. Nevertheless, two additional interesting features emerge from this picture. First, for coordinated interventions, one identifies a sharp increase in FX realized volatility between 14:00 and 15:00 (GMT+1), i.e. one hour after the beginning of the overlap period, i.e. simultaneous opening of both markets. Notice that the time lag between the opening of the European FX market (in Frankfurt) and the US market ranges between 5 and 7 hours. As reported by several authors including Dominguez (1998,

\footnotetext{
${ }^{14}$ Such a positive impact of CBI is also confirmed by Beine (2003) in a multivariate GARCH framework. Some noticeable exceptions to this positive impact are provided by Beine, Laurent and Lecourt (2003) using a volatility regime switching approach and by Mundaca (2001) accounting for exchange rate bands and simultaneity bias.

${ }^{15}$ We make use of the fact that at an hourly frequency, FX returns remain serially uncorrelated.
} 
2003), coordinated interventions between the Fed and the BB (ECB) primarily occur during the opening overlap period. Therefore, this means that the response of FX volatility to coordinated interventions is very fast, less than 1 hour, which is consistent with the findings of Dominguez(2003). The persistence of this effect can be studied by investigating the pattern of estimates drawn from rolling regressions (see below). This emphasizes the importance of quotation time of exchange rates for capturing the impact of FX interventions in a consistent way. The pattern of FX volatility changes in the boxplot displays some asymmetry, i.e. the size of the increases in the volatility during intervention days are not symmetrically distributed around the median. In particular, the positive impact of CBI seems to be higher in turbulent periods rather than in quiet markets.

While the boxplots provide numerous details about the timing and the persistence of the CBI's on the investigated realized moment, it is not suited to make inference. For this reason, rolling over all the possible value for $\theta(\theta=0, \ldots, 23)$, we regress the realized FX volatilities on the daily central bank intervention data. We pay attention to the statistical properties of the FX realized volatilities. Preliminary investigation and results reported in the literature suggest that the log of FX daily realized volatility is nearly gaussian, displays some long memory (Andersen et al. 1999) and is sensitive to a day of the week effect (Hsieh 1989). More precisely, DEM/USD realized volatilities tend to be higher on Monday than on other trading days of the week. In order to account for these features, we follow Andersen et al. (1999) in estimating an $\operatorname{ARFIMA}(1, d, 0)$ model which we extend by including a Monday dummy and more importantly dummy variables accounting for the types of CBI's as additional explanatory variables:

$$
(1-\phi L)(1-L)^{d}\left[\ln \left(\sigma_{t, \theta}^{2}\right)-\mu\right]=\epsilon_{t}+\mu_{t}
$$

where

$$
\begin{aligned}
\mu_{t} & =\beta_{0} I_{m, t}+\beta_{1} I_{B B U, t-i}+\beta_{2} I_{F E D U, t-i}+\beta_{3} I_{C O O R D, t-i} \\
& +\beta_{4} I_{F E D U Y, t}+\beta_{5} I_{B o J U, t}+\beta_{6} I_{C O O R D Y, t}
\end{aligned}
$$

in which $d$ (the fractional integration parameter), $\phi, \mu$, and the $\beta_{j}$ 's, $(j=0, \ldots, 6)$ are parameters to be estimated, $I_{m, t}$ is a dummy variable taking value 1 on Monday, and 0 otherwise. $I_{F E D U, t}$, $I_{B B U, t}, I_{C O O R D, t}, I_{F E D U Y, t}, I_{B o J U, t}, I_{C O O R D Y, t}$ are dummy variables taking value 1 when respectively a unilateral intervention of the Fed on the DEM/USD market, a unilateral intervention of the Bundesbank/ECB on the DEM/USD market, a coordinated intervention on the DEM/USD market, a unilateral intervention of the Fed on the YEN/USD market, a unilateral intervention of the BoJ on the YEN/USD market, a coordinated intervention on the YEN/USD market took place on day $t, 0$ otherwise. $\epsilon_{t}$ is the error term which is assumed to be normally and identically distributed. Estimating model (3) for each combination of the various possible values of indexes $i(i=-2,-1,0,1,2)$ and $\theta(\theta=0, \ldots, 23)$ one obtains a sequence of estimates of coefficients $\beta_{j}$ $(j=1, \ldots, 6)$, allowing to capture the evolution of the impact and the persistence of interventions across hours and days. The interventions carried out on the YEN/USD market are here only control variables, so that our interest lies in the evolution over time of $\beta_{1}, \beta_{2}$ and $\beta_{3}$. The models are estimated over the period January 41989 to February 28, 2001 (3061 points). Figure 4 reports the sequence of point estimates of respectively $\beta_{3}, \beta_{1}$ and $\beta_{2}$ as well as their confidence intervals at a $95 \%$ confidence level. Note that the information on the confidence intervals allows one to test the significance of the slope coefficients for specific values of $\theta$. 
Estimation of the ARFIMA models is carried out by exact maximum likelihood (Sowel 1992) under the normality assumption using ARFIMA 1.01 (see Doornik and Ooms 1999).

Insert Figure 4 about here.

Results from rolling regressions reinforce the previous conclusions drawn from the investigation of the boxplots but they also bring new insights. First, Figure 4 shows that unilateral interventions also exert significant effects on FX volatility, albeit less important than those exerted by coordinated interventions. Second, the timing on which they impact on FX volatility is quite different from the one particular to coordinated interventions: FX volatility seems to react to $\mathrm{BB}$ intervention in the morning (European time) while Fed interventions impact in the afternoon (US Eastern time). This is fully consistent with the fact that, without the need to coordinate and thus to take advantage of the market overlap, American and German authorities choose to conduct FX operations when only their local market is opened. Third and importantly, rolling estimates allow to characterize the persistence of coordinated and unilateral intervention. This is an important point, as there is a striking lack of consensus (both among academics and practitioners) about the typical horizon over which CBI's exert some significant impact (see the survey of Neely 2001 on this point). For coordinated interventions, in line with the evidence drawn from the boxplots (Figure 3), the pattern of $\beta_{3}$ estimates sharply increases at 15:00 GMT+1, i.e. one hour after the opening of the US market, confirming that the response to CBI is very fast. The significance of the $\beta_{3}$ estimates at time $t+1$ sharply drops after 16:00 GMT+1, i.e. after the closing of the German market. Given that a particular squared hourly return $r_{t, j}^{2}$ will be included in the next 24 measures of realized FX volatility, this means that this impact is of short duration, at most 2 hours. This finding has strong implications for approaches based on daily data. Choosing a wrong quotation time of the exchange rate is likely to lead to underestimation of the impact of CBI on exchange rate volatility. This point will be illustrated further in Section 4.

\subsection{Daily Volatility Spillover Effects}

In the literature not much attention is devoted to volatility spillover effects, i.e. changes of FX volatility on a particular market related to some intervention on another market. ${ }^{16}$ Nevertheless, in line with the extensive evidence on volatility spillovers between international stock markets (see for instance Koutmos and Booth, 1994), major exchange rate markets are likely to be highly interdependent. Therefore, news and financial events particular to a market are likely to exert volatility effects on the other markets. Using univariate GARCH models of DEM/USD and YEN/USD exchange rates over the 1985-1995 period, Dominguez (1998) does not detect any robust effect of this type. By contrast, in a multivariate GARCH framework, Beine (2002) finds that coordinated interventions on the YEN/USD market tend to increase exchange rate volatility on the DEM/USD market.

Focusing on the sequence of estimates of parameters $\beta_{4}, \beta_{5}$ and $\beta_{6}$ allows to document these volatility spillover effects. Figure 5 exhibits the presence of important volatility spillovers for all types of interventions, albeit less significant for unilateral Fed interventions. Once more, Figure 5 documents the intra-day variation of these effects. Volatility spillover effect of unilateral BoJ

\footnotetext{
${ }^{16}$ Note that one could of course also study the spillover effects on FX returns and higher moments. This has not been done as the impact of direct CBI's on these statistical measures has not been found to be substantial.
} 
interventions $\left(\beta_{5}\right)$ shows up at 1:00 $(\mathrm{GMT}+1)$, i.e. one hour after the opening of the Japanese market. Interestingly, like for volatility effects, the pattern of $\beta_{5}$ estimates suggests that the response to a CBI is very fast, at least one or two hours. Not surprisingly, the timing of BoJ impact contrasts with the one related to coordinated interventions $\left(\beta_{6}\right)$ which shows up in the US afternoon trading time. Basically, due to the absence of overlap between the Japanese and the US market and given that central banks generally prefer to intervene on their own market, coordinated interventions exert some impact when the Fed follows the BoJ, i.e. during the opening of the US market.

Insert Figure 5 about here.

\subsection{Daily Effects on Covariances and Correlations}

As suggested by the extensive literature on market contagion (see among others Forbes and Ribogon 1999), a CBI could also exert some significant spillovers in terms of covariance and correlation between exchange rates. One obvious reason is related to two distinct pieces of evidence. First, as reported by the core of empirical literature and fully confirmed by previous evidence reported above, CBI's tend to increase exchange rate uncertainty. Second, there is also strong evidence that correlations and/or covariances between asset prices are not constant over time (Engle, 2002). Furthermore, there is some evidence on the existence of a positive link between correlation and volatility pattern (see Andersen et al. 2001 for empirical evidence about exchange rates). Therefore, one might expect that CBI's that tend to induce increases in FX volatility also lead to a positive impact on cross-moments of exchange rates. There has been very little investigation of this particular point in the literature. The only evidence we are aware of is Beine (2003) showing from a multivariate GARCH model estimated on daily data that coordinated interventions on the YEN/USD market induced a strong and positive impact on both the covariance and the correlation between the YEN and the DEM against the USD. This result does not hold for unilateral interventions.

Empirical investigation in this particular field is highly constrained by the difficulties in handling and estimating multivariate GARCH models. In this perspective, realized covariances and correlations directly built from the intraday returns are useful for capturing such impacts. Realized covariances between the DEM/USD and the YEN/USD (denoted $\sigma_{t, \theta}^{d y}$ ) can then be computed in a similar way as realized variance:

$$
\sigma_{t, \theta}^{d y}=\sum_{j=0}^{23} c_{t, \theta-j}
$$

where $c_{t, j}$ denotes the instantaneous covariance (cross-product) between the DEM/USD and the YEN/USD peculiar to interval $j$ of day $t$. Realized correlation $\left(\rho_{t, \theta}\right)$ may also be directly computed as:

$$
\rho_{t, \theta}=\frac{\sigma_{t, \theta}^{d y}}{\sigma_{t, \theta}^{d} \sigma_{t, \theta}^{y}}
$$

in which $\sigma_{t, \theta}^{d}$ and $\sigma_{t, \theta}^{y}$ are the realized standard deviations of respectively the DEM/USD and the YEN/USD (see Subsection 2.4).

Figures 6 to 9 report the boxplots with respect to patterns of DEM/USD-YEN/USD covariances and correlations associated with coordinated and unilateral interventions. The graphs 
reported in Figures 6 and 7 suggest a strong positive response to coordinated interventions on covariance and to a lesser extent on correlation. Interestingly, the timing of the response of covariances is fully in line with those associated to exchange rate volatility (see Figure 4). Panel 1 of Figure 6 suggests that coordinated interventions on the DEM/USD also tend to increase exchange rate correlation. At first sight, the increase of cross-moments does not occur for unilateral interventions (see Figures 8 and 9). On the whole, these results are consistent with those obtained by Beine (2003) using a multivariate GARCH model on daily data. Once more, these results show that the impact displays much intradaily time variation.

Insert Figures 6-9 about here.

In order to complement the evidence of the boxplots, we run rolling regressions for the patterns of covariance responses to the different types of CBI's. The hyperbolic decay of the autocorrelations of the covariance calls for the use of a long memory model similar to the one fitted for the variances (see again Andersen et al. 2001). We estimate model (3) for the covariances replacing $\ln \left(\sigma_{t, \theta}^{2}\right)$ by $\ln \left(\sigma_{t, \theta}^{d y}\right)$. Like for the volatility analysis, we account for the different kinds of interventions on the markets of both currencies. The patterns of coefficient estimates $\left(\beta_{3}, \beta_{1}, \beta_{2}\right)$ related to interventions conducted by the Bundesbank and/or the Fed as well as their confidence intervals are reported in Figure 10. ${ }^{17}$ Panel 1 of this figure confirms the positive impact of coordinated interventions on the DEM/YEN covariance $\left(\beta_{3}\right)$. Interestingly, both the timing and the persistence of this effect are similar to those related to exchange rate volatility. The patterns of estimates reported in Panels 2 and 3 suggest that positive responses to unilateral interventions tend to hold, albeit that they are much lower in terms of size than for coordinated ones. As claimed by Beine (2003), accounting for these effects in terms of cross-moments is of high importance in many applications in portfolio and risk management of currencies.

Insert Figure 10 about here.

\subsection{Effects on Daily Higher Moments}

Very little research has been conducted in order to capture the impact in terms of higher moments, i.e. skewness and kurtosis. Skewness dynamics may be of particular interest since it captures the evolution of downside or upside risk on a particular market. Galati and Melick (1999) are the only ones who try to fill this gap. Using implied probability densities of market expectations at a one-month horizon drawn from currency option prices, they do not find any significant impact of perceived coordinated CBI's on third moments. They do not however focus on unilateral interventions which may also exert an important impact on first and second moments of exchange rate distributions and limit their investigation to perceived rather than official interventions. ${ }^{18}$ We are not aware of any study of the impact on ex post third and/or fourth moments. The lack of such studies is probably due to the difficulty of handling parametric models based on more general distributions than the symmetric Gaussian and Student distributions. One solution would be to consider the skewed Student density of Hansen (1994) with time-varying asymmetry parameter.

\footnotetext{
${ }^{17}$ In order to save space, we do not report the results related to interventions on the YEN/USD markets. They are similar to the results reported in Figure 9 but are available upon request.

${ }^{18}$ It is unclear whether the two series significantly differ from each other. The discrepancy depends on the occurrence of both secret interventions and false rumors.
} 
Nevertheless, estimation of a model with skewed distributions and time-dependent conditional moments is obviously cumbersome.

Alternatively, a simpler approach is to consider the realized skewness as suggested by Dacorogna et al. (2001). Naturally, the realized skewness is defined as:

$$
S k_{t, \theta}=\frac{\sum_{j=0}^{23} r_{t, \theta-j}^{3}}{\left(\sigma_{t, \theta}^{2}\right)^{3 / 2}}
$$

Insert Figures 11 and 12 about here.

The measure of realized skewness in (6) neglects any dependence between the terms $r_{t, \theta-j}^{2}$ and $r_{t, \theta-j .}{ }^{19}$ Boxplots of skewness dynamics (see Figure 11) suggest that skewness tends to react mainly to coordinated USD purchases. Coordinated purchases of dollars lead to strong decreases of realized skewness for both currencies. The timing of this effect seems consistent with the ones previously documented for the volatilities and the cross-moments, i.e. occurring after 15.00 GMT +1 . By contrast, coordinated USD sales and unilateral operations do not seem to exert any significant impact on the realized third moment.

Such an effect is confirmed by the results yielded by the rolling regressions. The specification used for capturing the impact of interventions on skewness differs from volatility models defined in (3) with respect to both the type of parametric models and the way interventions are defined. Preliminary analysis shows that there is a very fast decrease in the autocorrelations of $S k_{t, \theta}$, regardless the value of $\theta$. Therefore, a basic ARMA model seems sufficient to capture the dynamics of the daily realized skewness. Second, like for exchange returns, the sign of the intervention operation matters. Furthermore, boxplots reported in Figure 11 suggests that coordinated purchases of USD tend to exert much more important effects than coordinated sales. This implies than one should account for possible distinct effects of purchases and sales in the rolling regressions. Figures 13 and 14 display the patterns of the $\gamma$ coefficients estimated from the following models $(\theta=0, \ldots, 23 ; i=-2, \ldots, 2)$ :

$$
\begin{aligned}
& (1-\phi L)\left(S k_{t, \theta}-\gamma\right)=\epsilon_{t}+\gamma_{t} \\
& \text { where } \\
\gamma_{t} & =\gamma_{1} I_{C O O R D s, t-i}+\gamma_{2} I_{C O O R D p, t-i}+\gamma_{3} I_{B B U s, t-i} \\
& +\gamma_{4} I_{F E D U s, t-i}+\beta_{5} I_{F E D U p, t-i}
\end{aligned}
$$

The time-variation of the $\gamma_{2}$ coefficient in Figure 13 suggests that coordinated purchases of the Fed and the Bundesbank have some impact at the opening of the market overlap. Coordinated purchases of USD lead the market to put more weight on a appreciating dollar than to a weaker dollar, which confirms recent findings that central bank interventions can be effective in the (very) short run (Payne and Vitale, 2003). The effect of coordinated USD sales and unilateral operations on the DEM/USD market are much less striking (Figure 14).

\footnotetext{
${ }^{19}$ Using a standardized skewness measure as in (6) has the advantage of correcting for spurious time-dependence resulting possibly from time dependence in conditional volatility (see e.g. Korkie, Sivakumar and Turtle, 2003).
} 
The analysis can be extended to the investigation of the dynamics of the fourth realized moments. The time variation of the fourth moments is indicative of the time varying probability of occurrence of extreme events. A better understanding of its variation over time is of importance for financial applications such as risk management. This extension is left for future work.

Insert Figures 13 and 14 about here.

\subsection{Microstructure interpretation of the findings}

On the whole, our findings suggest that central bank interventions induce some jump in the dynamics of the exchange rate. ${ }^{20}$ The global picture is therefore fully consistent with the approach proposed by Vlaar and Palm (1993) in terms of a normal mixture specification with jumps. Beine and Laurent (2003) rely on a normal mixture model with a time varying jump probability related to the occurrence of (daily) central bank interventions. They show that coordinated interventions significantly increase the probability of a jump in the exchange rate. While there is no significant systematic change in the level in one or another particular direction, it increases the volatility. These findings are thus consistent with our results regarding the first and second realized moments. Nevertheless, unlike the analysis provided here, the normal mixture specification does not appropriately capture effects on higher moments. In this respect, our results show that this jump induces a change in the third moments.

Given the intradaily dimension of the analysis, it is interesting to relate our findings to the microstructure approach of financial assets. This literature distinguishes between two approaches, the inventory-based approach and the information-based approach respectively (see e.g. O'Hara, 1995 and Lyons, 2001). The inventory-based approach emphasizes the balancing problem on markets resulting from moderate (stochastic) deviations in inflows and outflows. These deviations could be the result of a CBI. In general, they are assumed to be unrelated to the future value of the asset traded but they can affect the short-run behavior of the market in terms of order flows, bid-ask spreads, transactions and prices. For the long run, assuming that market participants can adjust their positions and quotes, these differences in the fluctuations of inflows and outflows are irrelevant. Our findings on the impact of the CBI 's appear to be of a temporary nature only. In that respect our results are in agreement with the predictions from the inventory approach stressing the rebalancing in the market following a CBI (see also Dominguez, 2003). Our results appear to be in line with the predictions from the theoretical model by Evans and Lyons, 2001, that the generally predicted strong price effect resulting from portfolio rebalancing, turns out to be small if the order flow following a CBI is expected to be reversed as CB 's sterilize their intervention and whereby key fundamentals such as the money supply and interest rates remain unaffected. The transitory spillover effects from one foreign exchange market to the other are also likely to result from temporary portfolio rebalancing by CB 's.

\footnotetext{
${ }^{20}$ For the sake of robustness, we also carried out the boxplot and the regression analysis using isolated interventions. Interventions are defined as isolated if they are not followed by another intervention of the same type in the next two days. Alternatively, one could have suppressed sequences of successive interventions regardless the type of intervention (unilateral or coordinated) but this results in very few occurrences of events. On the whole, the results are robust for the second and third moments, somewhat less for the realized returns. Nevertheless, regarding this last case, one should emphasize that these results are found using quite a small number of events and are not uniform for each quantile. For the sake of brevity, these results are not reported here but are available upon request.
} 
The informational approach to micromarket structure focusses on the question how price formation takes place and how market participants learn about the market. High volatility corresponds to a period of much informed trading as informed traders can then hide the volume of their transactions more easily. The informational approach predicts an increase in transaction volume and volatility following a CBI. Once the intervention news has been revealed, transaction volume and prices should revert to pre-intervention levels. This is what we observe for volatility in our event studies of various types of interventions. Volatility increases in reaction to intervention news. Soon after a CBI, volatility returns to its pre-intervention level. Also, the finding that the CBI impact on volatility in high volatility periods is more pronounced than in low volatitily regimes is in line with the prediction from the information-based approach that longer-run effect are related to factors such as information processing. Turbulent market conditions require more time to revert to initial levels. Actually, both types of approaches provide little insight into how long adjustment processes take.

\section{Implications for Modelling the Impact of CBI}

One striking implication of our analysis lies in the emphasis on the importance of the quotation time of the exchange rate for capturing daily effects of CBI. The patterns of coefficients capturing the responses of CBI's in terms of volatility (Figure 4) suggest that the impact is of relatively short duration. Therefore, in a traditional analysis the choice of a particular quotation time may lead to underestimation of the impact on daily data.

In order to illustrate these effects, we conduct an analysis on daily data and capture the impact of CBI through the traditional GARCH analysis proposed in the main core of the literature. We choose three different quotation times, following three representative analyses of this literature on daily data: Bonser-Neal and Tanner (1996) who rely on option prices quoted at 11.00 am on the Philadelphia market (around 17:00 GMT+1) ${ }^{21}$, Dominguez (1998) who uses New York market close data (21:00 GMT+1) and Beine, Bénassy and Lecourt (2002a) who use mid-day exchange rate data on the Frankfurt market $(13 \mathrm{~h} 00 \mathrm{GMT}+1)$. For each quotation time $\theta(\theta=13.00,16.00$, 17.00 and 21.00 GMT+1), we capture the impact using the following GARCH model:

$$
\begin{aligned}
& r_{t, \theta}=\mu+\epsilon_{t, \theta}+\rho r_{t-1, \theta}, \quad \epsilon_{t, \theta} \mid \Omega_{t} \sim N\left(0, \sigma_{t, \theta}^{2}\right) \\
& \sigma_{t, \theta}^{2}=\omega+\alpha \epsilon_{t-1, \theta}^{2}+\beta \sigma_{t-1, \theta}^{2}+\delta_{0} I_{m, t}+\delta_{1} I_{C O O R D, t-i}+\delta_{2} I_{F E D U, t-j}+\delta_{3} I_{B B U, t-h}
\end{aligned}
$$

in which $r_{t, \theta}$ is the daily return of the DEM/USD exchange rate computed at time $t$ and hour $\theta$ and $I_{C O O R D, t}, I_{F E D U, t}, I_{B B U, t}$ are the variables indicating intervention operations at time $t$ as defined previously in equation (3). One well-known problem related to the use of daily data is the choice of the lag in defining the intervention variables. Basically, one must ensure that these variables are predetermined in order to control for the simultaneity bias (excess volatility causing interventions) and to make sure that the intervention operations occur before the quotation of the exchange rate. This means that depending on the time quotation, one has to lag some or all the intervention variables. For instance, the choice of the quotation time by Dominguez (1998)

\footnotetext{
${ }^{21}$ Bonser-Neal and Tanner (1996) use implied volatilities drawn from currency option prices in order to capture the impact of CBI in terms of expected volatility. Nevertheless, this analysis obviously belongs to the core of studies based on daily data.
} 


\begin{tabular}{lcccc} 
& $\theta=13$ & $\theta=16$ & $\theta=17$ & $\theta=21$ \\
\hline \multirow{3}{*}{$\delta_{1}[$ COORD, $\mathrm{t}-\mathrm{i}]$} & $i=j=1 ; h=0$ & $i=0 ; j=1 ; h=0$ & $i=0 ; j=1 ; h=0$ & $i=j=h=0$ \\
& 0.076 & 0.204 & 0.117 & 0.023 \\
$\delta_{2}[$ FEDU,t-j] & {$[0.031]$} & {$[0.057]$} & {$[0.041]$} & {$[0.022]$} \\
& 0.000 & -0.012 & -0.011 & 0.002 \\
$\delta_{3}[$ BBU,t-h $]$ & {$[0.041]$} & {$[0.011]$} & {$[0.009]$} & {$[0.009]$} \\
& -0.003 & -0.023 & -0.013 & 0.005 \\
& {$[0.041]$} & {$[0.051]$} & {$[0.042]$} & {$[0.032]$} \\
\hline
\end{tabular}

Table 1: CBI volatility effects in a GARCH framework and quotation times Note: Robust standard errors are reported between brackets.

(21h00 GMT+1) ensures that all interventions of the Bundesbank and the Fed occured before: this allows to use interventions at time $t(i=j=h=0)$. Nevertheless, such a quotation time might not be appropriate to capture volatility spillover effects due to unilateral BoJ interventions since these take place at the opening of the Tokyo market, i.e. after 0:00 GMT+1. The choice of the quotation time in Bonser-Neal and Tanner (1996) requires to lag unilateral intervention of the Fed $(i=h=0 ; j=1)$. The lagging procedure for the coordinated interventions and the unilateral intervention of the Bundesbank is not required as the European markets are closed at that time. The same holds for the unilateral interventions of the Bundesbank when using the Beine, Bénassy and Lecourt (2002) quotation time if one assumes that most unilateral interventions of the Bundesbank occur in the morning trading time in Europe (this assumption might be too stong, of course); by contrast, it is strictly necessary to lag coordinated and unilateral interventions of the Fed $(i=j=h=1)$.

We focus here on the results peculiar to the impact of coordinated interventions. ${ }^{22}$ Tables 2 reports the estimation results for the various quotation times. Strikingly, the results suggest that the quotation time of the exchange rate is crucial to capture both the size and the significance of the impact of coordinated interventions in terms of exchange rate volatility. If one uses the quotes at the close of the German market $(\theta=16.00)$, the impact of coordinated interventions is substantial and highly significative. If one uses the quotation time of Bonser-Neal and Tanner (1996) (one hour later, $\theta=17.00$ ), while the model captures the high significance of these coordinated interventions, the impact has dramatically decreased. This is due to the short duration of volatility effects of these interventions which was previously documented through the pattern of realized volatility responses. The use of quotation time as in Dominguez(1998) -which makes sense because of the issue of simultaneity- does not allow to capture- at least over our investigation period- the impact of coordinated interventions. Both the size of the impact and the significance in the GARCH specification dramatically drop with respect to the previous quotation time. Once again, the reason is that the effect does not last beyond a 3 hours duration. Therefore, these results also shed a light on the crucial importance of choosing the appropriate quotation time in daily analysis of CBI's. Interestingly, they suggest that due to the simultaneity bias and the short duration of the effects which was emphasized in Section 2, one single GARCH model may be insufficient

\footnotetext{
${ }^{22}$ It turns out that the GARCH estimations do not capture any effect of unilateral interventions on the conditional volatility. This slightly contrasts with the results obtained from realized volatility.
} 
to fully capture the various effects associated with each kind of intervention. This stresses one important drawback of using daily data.

\section{Conclusions}

In this paper we have studied the impact of CBI's on foreign exchange markets for the DEM/USD and YEN/USD. We have carried out event studies for interventions days, the two days preceding an intervention and two days following an intervention using realized intraday moments to measure the impact of CBI's. We have looked at the impact of interventions on returns and return volatility. CBI's appear not to have a significant impact on the returns. Coordinated interventions do have an impact on return volatility. In line with the existing literatiure, this effect appears to be significant. Nevertheless, our analysis allows to document its persistence and show that it is of a temporary nature, at most a few hours. To the extent that CBI's were aimed at reducing exchange rate volatility (see Almekinders and Eijffinger, 1994, for empirical evidence from CB reaction functions) these interventions appear not to have been effective.

Our approach based on realized moments allows to test for the impact on cross-moments of exchange rate returns as well as on higher moments without having to model these moments. Realized daily covariances are affected by CBI's as well and the timing of the impact is consistent with the one associated to volatilities. Our results tend to confirm previous findings of the literature based on multivariate GARCH models and document the persistence of these effects. While positive, the impact of coordinated interventions on correlations however has not been found to be substantial. Interestingly, the impact of coordinated CBI's on realized intraday skewness measures is apparent in the boxplots as well. The impact on the kurtosis could easily be analyzed using the same approach but is left for future work. A striking finding of the paper is that any impact of CBI's appears to be of a temporary nature, which is line with the findings of Dominguez (2003) for the first two moments. The results for the boxplots are confirmed by those from the analysis of rolling regressions.

Our comprehensive empirical analysis has both implications for policy-making and for empirical modelling of foreign exchange rates. The following conclusions might be relevant for policy making at Central Banks. In the past, even through coordinated interventions Central Banks appear not to have been effective in influencing DEM/USD exchange rate returns. When coordinating their interventions Central Banks have achieved a significant, albeit temporary effect on exchange rate volatility, covariance and to a lesser extent skewness. The question whether these effects have been intended and/or have been desired can not be answered on the basis of the statistical information studied.

For a modelling purpose it is important to conclude that the impact of CBI's does not extend beyond the intervention day. This conclusion implies that in an analysis of daily data, the impact of CBI's can be accounted for by including dummy variables for the (coordinated) intervention days only in those moments that have been found to be sensitive to CBI's in the past. Notice that a CBI impact on realized moments that extends beyond the intervention day is usually due to the moving average feature of realized moments. 


\section{References}

[1] Andersen, T., and T. Bollerslev, 1997. Intraday Periodicity and Volatility Persistence in Financial Markets. Journal of Empirical Finance, 4, 115-158.

[2] Andersen, T., and T. Bollerslev, 1998. DM-Dollar Volatility: Intraday Activity, Macroeconomic Announcements,and Longer-Run Dependencies. Journal of Finance, 4, 115-158.

[3] Andersen, T.G., T. Bollerslev, F.X. Diebold, and P. Labys, 1999, Realized Volatility and Correlation, L.N. Stern School of Finance Department Working Paper 24.

[4] Andersen, T.G., T. Bollerslev, F.X. Diebold, and P. Labys, 2001, The Distribution of Realized Exchange Rate Volatility. Journal of the American Statistical Association, 96, 42-55.

[5] Andersen, T.G., T. Bollerslev, F.X. Diebold, and P. Labys, 2002, Modeling and Forecasting Realized Volatility, Econometrica, 71, 579-625.

[6] Almekinders, G.J., and S.C.W. Eijffinger, 1994, Daily Bundesbank and Federal Reserve Informations: Are They a Reaction to Changes in the Level and Volatility of the USD/DM-Rate?, Empirical Economics, 19, 111-130.

[7] Baillie R.T., O.M. Humpage, and W.P. Osterberg, 2000, Intervention from an Information Perspective, Journal of International Financial Markets, Institutions and Money, 10, 407-421.

[8] Baillie, R.T., and W.P. Osterberg, 1997a, Why do Central Banks Intervene ?, Journal of International Money and Finance, 16 (6), 909-919.

[9] Baillie, R.T., and W.P. Osterberg, 1997b, Central Bank Intervention and Risk in the Forward market, Journal of International Economics, 43, 483-497.

[10] Barndorff-Nielsen, O.E., and N. Shephard, 2002, Econometric Analysis of Realized Volatility and its Use in Estimating Stochastic Volatility Models, Journal of the Royal Statistical Society $B, 64,253-280$.

[11] Beine, M., 2003, Conditional Covariances and Direct Central Bank Interventions in the Foreign Exchange Markets, forthcoming in the Journal of Banking and Finance.

[12] Beine, M., A. Bénassy-Quéré, and C. Lecourt, 2002, Central Bank Intervention and Foreign Exchange Rates: New Evidence from FIGARCH estimations. Journal of International Money and Finance, 21, 115-144.

[13] Beine, M., and S. Laurent, 2003, Central Bank Interventions and Jumps in Double Long Memory Models of Daily Exchange Rates. Journal of Empirical Finance, 10, 641-660.

[14] Beine, M., S. Laurent, and C. Lecourt, 2003, Official central bank interventions and exchange rate volatility: evidence from a regime switching analysis. European Economic Review, 47, 891-911.

[15] Bonser-Neal, C., and G. Tanner, 1996, Central Bank Intervention and the Volatility of Foreign Exchange Rates : Evidence from the Options Market, Journal of International Money and Finance, 15 (6), 853-878. 
[16] Catte, P., G. Galli, and S. Rebecchini, 1992, Exchange Markets Can Be Managed!, Report on the G-7, International Economic Insights.

[17] Chang, Y., and S. Taylor, 1998, Intraday Effects of Foreign Exchange Intervention by the Bank of Japan, Journal of International Money and Finance, 17, 191-210.

[18] Dacorogna, M.M., R. Gencay, U.A. Müller, R.B. Olsen, and O.V. Pictet, 2001, An Introduction to High-Frequency Finance, Academic Press, London.

[19] Dominguez, K.M., 1998, Central bank Intervention and Exchange Rate Volatility, Journal of International Money and Finance, 17, 161-190.

[20] Dominguez K.M., 1999, The Market Microstructure of Central Bank Intervention, NBER Working Paper 7337.

[21] Dominguez K.M., 2003, The Market Microstructure of Central Bank Intervention, Journal of International Economics, 59, 25-45.

[22] Dominguez, K.M., and J. Frankel, 1993, Does Foreign Exchange Intervention Work ?, Institute for International Economics, Washington, DC.4.

[23] Doornik, J. A., and M. Ooms, 1999, A Package for Estimating, Forecasting and Simulating Arfima models: Arfima package 1.0 for Ox, Discussion paper, Econometric Institute, Erasmus University Rotterdam.

[24] Engle, R.F., 2002, Dynamic Conditional Correlation - a Simple Class of Multivariate GARCH Models, Journal of Business and Economic Statistics, 20, 339-350.

[25] Evans, M.D.D., and R.K. Lyons, 2001, Portfolio Balance, Price Impact, and Secret Intervention, forthcoming in Financial Market Structure and Dynamics, Bank of Canada.

[26] Forbes, K., and R. Ribogon, 1999, No contagion, only Interdependence: Measuring Stock Market Co-movements. NBER Working Paper 7267. National Bureau of Economic Research, Cambridge, Mass.

[27] Galati, G., and W. Melick, 1999, Perceived Central Bank Intervention and Market Expectations: an Empirical Study of the YEN/Dollar Exchange Rate, 1993-1996, BIS Working Paper 77.

[28] Hansen, B.E., 1994, Autoregressive Conditional Density Estimation, International Economic Review, 35, 705-730.

[29] Hsieh, D.A., 1989, Modeling Heteroskedasticity in Daily Foreign Exchange Rates, Journal of Business and Economic Statistics, 7, 3, 307-317.

[30] Ito, T., 2002, Is Foreign Exchange Intervention Effective? The Japanese Experiences in the 1990's. NBER Working paper No. 8914.

[31] Korkie, B., R. Sivakumar, and H. Turtle, 2003, Spurious Skewness Persistence in Financial Asset Returns, University of Waterloo, Canada. 
[32] Koutmos, G., and G.G. Booth, 1994, Asymmetric Volatility Transmission in International Stock Market, Journal of International Money and Finance, 14(6), 747-62.

[33] Lyons, R. K., 2001, The Microstructure Approach to Exchange Rates, The MIT Press, Cambridge, MA.

[34] Mundaca, G.B., 2001, Central Bank Interventions and Exchange Band Regimes, Journal of International Money and Finance, 20, 677-700.

[35] Murray, J., Zelner, M., and D. McManus, 1997, The Effect of Intervention on Canadian Dollar Volatility Exchange Rates and Monetary Policy, Proceedings of a Conference held at the Bank of Canada Octover 1996, Bank of Canada, Ottawa, 311-361.

[36] Mussa, M., 1981, The Role of Official Intervention, Group of Thirty Occasional Papers no. 6, Group of Thirty, New York.

[37] Neely, C. J., 2001, The Practice of Central Bank Intervention: Looking under the Hood, Federal Reserve Bank of Saint-Louis Review, 83(3).

[38] O'Hara, M., 1995, Market Microstructure Theory, Basic Blackwell, Oxford.

[39] Payne, R., and P. Vitale, 2003, A transaction level study of the effects of central Bank Interventions on exchange rates, Journal of International Economics, 61, 331-352.

[40] Sarno, L., and M.P. Taylor, 2001, Official intervention in the foreign exchange market: is it effective and, if so, how does it work? Journal of Economic Literature 39(3), 839-868.

[41] Sowel, F., 1992, Maximum Likelihood Estimation of Stationary Univariate Fractionally Integrated Time Series Models, Journal of Econometrics, 53, 165-188.

[42] Tse, Y.K., 1998, The Conditional Heteroskedasticity of the YEN-Dollar Exchange Rates, Journal of Applied Econometrics, 13, 1, 49-56.

[43] Vlaar, P.J.G., and F.C. Palm, 1993, The Message in Weekly Exchange Rates in the European Monetary System: Mean Reversion, Conditional Heteroskedasticity and Jumps, Journal of Business and Economic Statistics 11, 351-360. 


\section{Appendix 1: Data}

\section{Exchange Rate Data}

Our dataset contains hourly data for two major exchange rates, the Japanese Yen (YEN) and the Deutsche Mark (DEM)(Euro after 1998) against the US Dollar (USD). For these two exchange rates, we have about 12 years of intraday data, from January 1989 to February 2001. The raw data consists of all interbank USD-Euro(DEM) and YEN-USD bid-ask quotes displayed on the Reuters FX screen during this period. Note that intraday FOREX returns computed from quoted bid-ask prices are subject to various market microstructure 'frictions', e.g. strategic quote positioning and inventory control. Such features are generally immaterial when analyzing longer horizon returns, but may distort the statistical properties of the underlying 'fundamental' high-frequency intraday returns. The sampling frequency for which such considerations become a concern is intimately related to market activity. For our exchange rate series, preliminary analysis based on the methods of Andersen, Bollerslev, Diebold and Labys (2002) suggest that the use of equallyspaced thirty-minute or hourly returns strikes a satisfactory balance between the accuracy of the continuous-record asymptotics underlying the construction of our realized volatility measures on the one hand, and the confounding influences from the market microstructure frictions on the other. As standard in the literature, we compute hourly exchange rate prices from the linearly interpolated average of the logarithms of bid and ask quotes for the two ticks immediately before and after the hourly time stamps throughout the global 24-hour trading day. Next we obtain hourly returns as 100 times the first difference of the equally time-spaced logarithmic prices.

\section{Official Central Bank Intervention Data (1989-2001)}

The data used in this paper are official data of central bank interventions in the FX market.

- For the Fed, all data have been transmitted by the Federal reserve;

- For the Bundesbank, all data have been transmitted by the Bundesbank; the data after 1998 are reported interventions of the ECB, which nevertheless confirmed the 4 interventions carried out in September and November 2000 (but did not release the amounts);

- For the BoJ, the data after April 11991 are official data released by the BoJ (http://www.mof.go.jp./english/e1c021.htm). Official interventions before April 1991 are proxied by reported interventions in the Financial press (Wall Street Journal and Financial Times) (see Beine et al. 2002a for more details).

Table (A1) presents the number of occurrences of each kind of interventions carried out by the Fed, the Bundesbank (ECB) and the BoJ in the two exchange rate markets. All interventions (except those of the Bank of Japan since 2002) have been sterilized according to the statements of the CB's. 
DEM-USD

\begin{tabular}{ccccccc}
\multicolumn{2}{c}{ Unilateral FED } & \multicolumn{2}{c}{ Unilateral BB } & \multicolumn{2}{c}{ Coordinated } & Total \\
\hline USD purchases & USD sales & USD purchases & USD sales & USD purchases & USD sales \\
26 & 34 & 0 & 33 & 14 & 44 & 151 \\
\hline \multicolumn{2}{c}{ Unilateral FED } & \multicolumn{2}{c}{ YEN-USD } & Coordinated & Total \\
\hline \multicolumn{2}{c}{31} & Unilateral BoJ & & 72 & 281
\end{tabular}

Table A1: Number of central bank intervention days

\section{Appendix 2: ARFIMA Estimation of Exchange Rate Real- ized Volatility}

This appendix reports examples of rolling regression estimation results for the parameters $\beta_{i}$ reported in Figures 4 and 5. Measures of the fit of the ARFIMA models for realized FX volatility are given as well. Table A1 reports estimation results of model (3) with fixed $i(i=0)$ for the intervention variables specific to the YEN/USD market $\left(I_{F E D U Y, t-i}, I_{B o J U, t-i}, I_{C O O R D Y, t-i}\right)$. In other words, only contemporaneous interventions on the YEN/USD are introduced as control variables.

$$
\begin{aligned}
& \quad(1-\phi L)(1-L)^{d}\left[\ln \left(\sigma_{t, \theta}^{2}\right)-\mu\right]=\mu_{t}+\epsilon_{t} \\
& \quad \text { where } \\
& \begin{aligned}
\mu_{t} & =\beta_{0} I_{m, t}+\beta_{1} I_{B B U, t-i}+\beta_{2} I_{F E D U, t-i}+\beta_{3} I_{C O O R D, t-i} \\
& +\beta_{4} I_{F E D U Y, t}+\beta_{5} I_{B o J U, t}+\beta_{6} I_{C O O R D Y, t}
\end{aligned}
\end{aligned}
$$

Estimates reported in Table A2 confirm that the model reproduces some of the main features of FX realized volatility:

- Long memory: the $d$ parameter lies between 0 and 1 , with a value of approximately 0.3 , suggesting persistence of volatility shocks and a covariance stationary process; notice that the value of $\mathrm{d}$ is consistent with values obtained for the fractional integration parameter estimated in FIGARCH models of FX data (Tse 1998).

- Day-of-the-week effect: the $\alpha$ parameter is significantly positive, confirming previous findings (Hsieh 1989) of a positive Monday dummy effect on volatility. 


\begin{tabular}{|c|c|c|c|c|c|c|}
\hline \multirow[b]{2}{*}{ parameters } & \multicolumn{2}{|c|}{$i=1$} & \multicolumn{2}{|c|}{$i=0$} & \multicolumn{2}{|c|}{$i=-1$} \\
\hline & $\theta=6$ & $\theta=15$ & $\theta=6$ & $\theta=15$ & $\theta=15$ & $\theta=17$ \\
\hline \multirow[t]{2}{*}{$d$} & 0.378 & 0.372 & 0.377 & 0.374 & 0.373 & 0.362 \\
\hline & {$[0.019]$} & {$[0.019]$} & {$[0.019]$} & [0.019] & {$[0.019]$} & $(0.019]$ \\
\hline \multirow[t]{2}{*}{$\mu$} & -1.101 & -1.088 & -1.099 & -1.102 & -1.109 & -1.059 \\
\hline & {$[0.291]$} & {$[0.274]$} & {$[0.289]$} & {$[0.277]$} & {$[0.277]$} & {$[0.254]$} \\
\hline \multirow[t]{2}{*}{$\phi$} & -0.101 & -0.091 & -0.099 & -0.096 & -0.094 & -0.057 \\
\hline & {$[0.026]$} & {$[0.026]$} & {$[0.026]$} & {$[0.026]$} & {$[0.026]$} & {$[0.026]$} \\
\hline \multirow[t]{2}{*}{$\alpha$} & 0.320 & 0.195 & 0.320 & 0.197 & 0.190 & 0.009 \\
\hline & {$[0.027]$} & {$[0.027]$} & {$[0.027]$} & {$[0.027]$} & {$[0.027]$} & {$[0.027]$} \\
\hline \multirow[t]{2}{*}{$\beta_{1}[\mathrm{BBU}, \mathrm{t}-\mathrm{i}]$} & 0.088 & 0.117 & 0.196 & 0.370 & 0.011 & -0.075 \\
\hline & {$[0.116]$} & {$[0.116]$} & {$[0.116]$} & {$[0.115]$} & {$[0.115]$} & {$[0.115]$} \\
\hline \multirow[t]{2}{*}{$\beta_{2}[\mathrm{FEDU}, \mathrm{t}-\mathrm{i}]$} & 0.068 & -0.040 & -0.124 & -0.171 & 0.236 & 0.168 \\
\hline & {$[0.098]$} & {$[0.097]$} & {$[0.103]$} & {$[0.103]$} & {$[0.097]$} & {$[0.097]$} \\
\hline \multirow[t]{2}{*}{$\beta_{3}[\mathrm{COORD}, \mathrm{t}-\mathrm{i}]$} & -0.032 & -0.161 & -0.165 & -0.171 & 0.348 & 0.088 \\
\hline & {$[0.097]$} & {$[0.096]$} & {$[0.104]$} & {$[0.103]$} & {$[0.097]$} & {$[0.097]$} \\
\hline \multirow[t]{2}{*}{$\beta_{4}[\mathrm{FEDUY}, \mathrm{t}]$} & 0.066 & 0.074 & 0.129 & 0.002 & 0.061 & 0.143 \\
\hline & {$[0.127]$} & {$[0.127]$} & {$[0.133]$} & {$[0.132]$} & {$[0.127]$} & {$[0.126]$} \\
\hline \multirow[t]{2}{*}{$\beta_{5}[\mathrm{BoJU}, \mathrm{t}]$} & 0.249 & 0.379 & 0.242 & 0.364 & 0.381 & 0.325 \\
\hline & {$[0.059]$} & {$[0.059]$} & {$[0.059]$} & {$[0.059]$} & {$[0.059]$} & {$[0.059]$} \\
\hline \multirow[t]{2}{*}{$\beta_{6}[\mathrm{COORDY}, \mathrm{t}]$} & 0.076 & 0.258 & 0.141 & 0.201 & 0.252 & 0.335 \\
\hline & {$[0.093]$} & {$[0.093]$} & {$[0.100]$} & {$[0.100]$} & {$[0.093]$} & {$[0.093]$} \\
\hline Ljung Box (50) & 59.97 & 65.37 & 60.66 & 62.04 & 63.66 & 86.88 \\
\hline Ljung Box (100) & 102.59 & 123.34 & 104.35 & 122.41 & 119.30 & 133.97 \\
\hline $\operatorname{Arch}(20)$ & 1.41 & 1.75 & 1.41 & 1.77 & 1.64 & 2.07 \\
\hline
\end{tabular}

Table A2: Sample of rolling estimations 


\section{Appendix 3: Assumptions and properties of realized mo- ments}

When computing the realized moments for closing prices (24h GMT), daily returns are defined as: $r_{t}=\sum_{i=1}^{K} r_{i, t}$, where $K$ is the number of intervals per day (e.g. 24 ) and $r_{i, t}$ is the ith intraday return of day $t$.

\section{1: Realized volatility}

Consider two measures of the daily volatility $V\left(r_{t}\right): V_{1, t} \equiv r_{t}^{2}$, i.e. daily squared returns, and $V_{2, t} \equiv \sum_{i=1}^{K} r_{i, t}^{2}$, i.e. the so-called realized volatility.

Assumption $A_{1}: r_{i, t}$ is a martingale difference sequence (MDS), i.e. $E\left(r_{i, t} \mid \Omega_{i-1, t}\right)=0$, where $\Omega_{i-1, t}$ denotes a filtration (information set) including past information on $r$ up to (and including) the point in time $i-1$ on day $t$.

\section{Implications of Assumption $A_{1}$ :}

1. $E\left(r_{i, t}\right)=0$;

2. $\operatorname{Cov}\left(r_{i, t}, r_{j, t^{\prime}} \mid \Omega_{\max (i-1, j-1), \max \left(t, t^{\prime}\right)}\right)=0$, which implies $\operatorname{Cov}\left(r_{i, t}, r_{j, t^{\prime}}\right)=0$;

3. $E\left(r_{i, t} r_{j, t^{\prime}}^{k} \mid \Omega_{i-1, t}\right)=0$ if $i>j$ and $t \geq t^{\prime}, k \in\{1,2, \ldots\}$.

The implications follow immediately when we use the law of iterated expectations. Note that Assumption $A_{1}$ does not imply that $E\left(r_{i, t} r_{j, t^{\prime}}^{k} \mid \Omega_{j-1, t^{\prime}}\right)=0$ if $i \leq j, t<t^{\prime}$.

Proposition 1: Under $A_{1}, V_{1, t}$ and $V_{2, t}$ are unbiased estimators of $V\left(r_{t}\right)$.

Proof:

$$
\begin{array}{rl}
E\left(V_{1, t}\right) & =E(r_{t}^{2} \underbrace{=}_{A_{1}} V\left(r_{t}\right) \\
V\left(r_{t}\right) \underbrace{=}_{A_{1}} E\left(r_{t}^{2}\right) & \\
& =E\left(\left(\sum_{i=1}^{K} r_{i, t}\right)^{2}\right) \\
& =E\left(\sum_{i=1}^{K} r_{i, t}^{2}+2 \sum_{i=1}^{K-1} \sum_{j=1}^{K} r_{i, t} r_{j, t}\right) \\
\underbrace{=}_{A_{1}} & E\left(\sum_{i=1}^{K} r_{i, t}^{2}\right) \\
= & E\left(V_{2, t}\right) .
\end{array}
$$

Assumption $A_{2}: E\left(r_{i, t} r_{j, t}^{3} \mid \Omega_{j-1, t}\right)=0 \forall i<j$.

$\Rightarrow$ Assumption of zero skewness of some conditional distribution / symmetry of the conditional distributions. 
Proposition 2: Under $A_{1}-A_{2}, V_{2, t}$ is a more efficient estimate of $V\left(r_{t}\right)$ than $V_{1, t}$.

Proof: for simplicity let us consider the case where $K=2$.

$$
\begin{array}{rl}
E\left(V_{1, t}^{2}\right) & =E\left(\left(r_{1, t}+r_{2, t}\right)^{4}\right) \\
& =\quad E\left(r_{1, t}^{4}+r_{2, t}^{4}+4 r_{1, t}^{3} r_{2, t}+4 r_{1, t} r_{2, t}^{3}+6 r_{1, t}^{2} r_{2, t}^{2}\right) \\
\underbrace{=}_{A_{1}-A_{2}} & E\left(r_{1, t}^{4}+r_{2, t}^{4}+6 r_{1, t}^{2} r_{2, t}^{2}\right)
\end{array}
$$

More generally, it follows that:

$$
E\left(V_{1, t}^{2}\right)=E\left(\sum_{i=1}^{K} r_{i, t}^{4}+3 \sum_{i=1}^{K} \sum_{j \neq i}^{K} r_{i, t}^{2} r_{j, t}^{2}\right)
$$

Similarly, for $V_{2, t}$,

$$
\begin{aligned}
E\left(V_{2, t}^{2}\right) & =E\left(\left(r_{1, t}^{2}+r_{2, t}^{2}\right)^{2}\right) \\
& =E\left(r_{1, t}^{4}+r_{2, t}^{4}+2 r_{1, t}^{2} r_{2, t}^{2}\right)
\end{aligned}
$$

or more generally:

$$
E\left(V_{2, t}^{2}\right)=E\left(\sum_{i=1}^{K} r_{i, t}^{4}+\sum_{i=1}^{K} \sum_{j \neq i}^{K} r_{i, t}^{2} r_{j, t}^{2}\right)
$$

Since $r_{i, t}^{2} r_{j, t}^{2} \geq 0$, it follows directly that $E\left(V_{1, t}^{2}\right) \geq E\left(V_{2, t}^{2}\right)$ and since $E\left(V_{1, t}\right)=E\left(V_{2, t}\right)=V\left(r_{t}\right)$, $V\left(V_{1, t}\right)>V\left(V_{2, t}\right)$.

Note that the proof could be done in terms of conditional expected values as well.

\section{2: Realized skewness}

Recall that the skewness is defined as: $\frac{E\left[\left(r_{t}-E\left(r_{t}\right)\right)^{3}\right]}{E\left(r_{t}^{2}\right)^{3 / 2}} \underbrace{=}_{A_{1}} \frac{E\left(r_{t}^{3}\right)}{E\left(r_{t}^{2}\right)^{3 / 2}}$.

For this reason a first measure of the daily cube returns is naturally $S_{1, t} \equiv r_{t}^{3}$. Extending the idea of realized volatility to the third moment would suggest the estimator $S_{2, t} \equiv \sum_{i=1}^{K} r_{i, t}^{3}$.

Is $S_{2, t}$ an unbiased estimator of $E\left(r_{t}^{3}\right)$ ?

Assumption $A_{3}$ : $E\left(r_{i, t}^{2} r_{j, t} \mid \Omega_{j-1, t}\right)=0 \forall i>j$.

Proposition 3: Under $A_{1}, A_{3}, S_{2, t}$ is an unbiased estimator of $E\left(r_{t}^{3}\right)$.

Proof: for simplicity let us consider the case where $K=2$.

$$
\begin{array}{rl}
E\left(r_{t}^{3}\right) & =E\left(\left(r_{1, t}+r_{2, t}\right)^{3}\right) \\
& =E\left(r_{1, t}^{3}+r_{2, t}^{3}+3 r_{1, t}^{2} r_{2, t}+3 r_{1, t} r_{2, t}^{2}\right) \\
\underbrace{=}_{A_{1}, A_{3}} & E\left(r_{1, t}^{3}+r_{2, t}^{3}\right) \\
= & E\left(S_{2, t}\right)
\end{array}
$$


Which of the two estimators dominates in terms of efficiency depends on sign and size of higher moments as the simple case when $K=2$ shows.

Proof:

$$
\begin{array}{rl}
E\left(S_{1, t}^{2}\right) \underbrace{=}_{A_{1}} & E\left(\left(r_{1, t}+r_{2, t}\right)^{6}\right) \\
& =E\left(r_{1, t}^{6}+r_{2, t}^{6}+6 r_{1, t} r_{2, t}^{5}+15 r_{1, t}^{2} r_{2, t}^{4}+20 r_{1, t}^{3} r_{2, t}^{3}+15 r_{1, t}^{4} r_{2, t}^{2}\right) \\
E\left(S_{2, t}^{2}\right) \underbrace{=}_{A_{1}, A_{3}} & E\left(\left(r_{1, t}^{3}+r_{2, t}^{3}\right)^{2}\right) \\
= & E\left(r_{1, t}^{6}+r_{2, t}^{6}+2 r_{1, t}^{3} r_{2, t}^{3}\right) \\
& \\
& \\
E\left(S_{1, t}^{2}\right)-E\left(S_{2, t}^{2}\right) \underbrace{=}_{A_{1}, A_{6}} & E\left(18 r_{1, t}^{3} r_{2, t}^{3}\right) \\
& +\quad E\left(6 r_{1, t} r_{2, t}^{5}\right) \\
& +\quad E\left(15 r_{1, t}^{2} r_{2, t}^{4}\right) \\
& +\quad E\left(15 r_{1, t}^{4} r_{2, t}^{2}\right) \\
& \underbrace{>}_{?}
\end{array}
$$

Assuming independence over time of the intradaily returns, which implies Assumption A3, and assuming a symmetric distribution around the mean of these returns, we get that $E\left(r_{1, t}^{3} r_{2, t}^{3}\right)=0$ and $E\left(r_{1, t} r_{2, t}^{5}\right)=0$. In that case, $E\left(S_{1, t}^{2}\right)-E\left(S_{2, t}^{2}\right)=E\left(15 r_{1, t}^{2} r_{2, t}^{4}\right)+E\left(15 r_{1, t}^{4} r_{2, t}^{2}\right)>0$, which implies that $S_{2, t}$ is more efficient than $S_{1, t}$. 


\section{Figures}
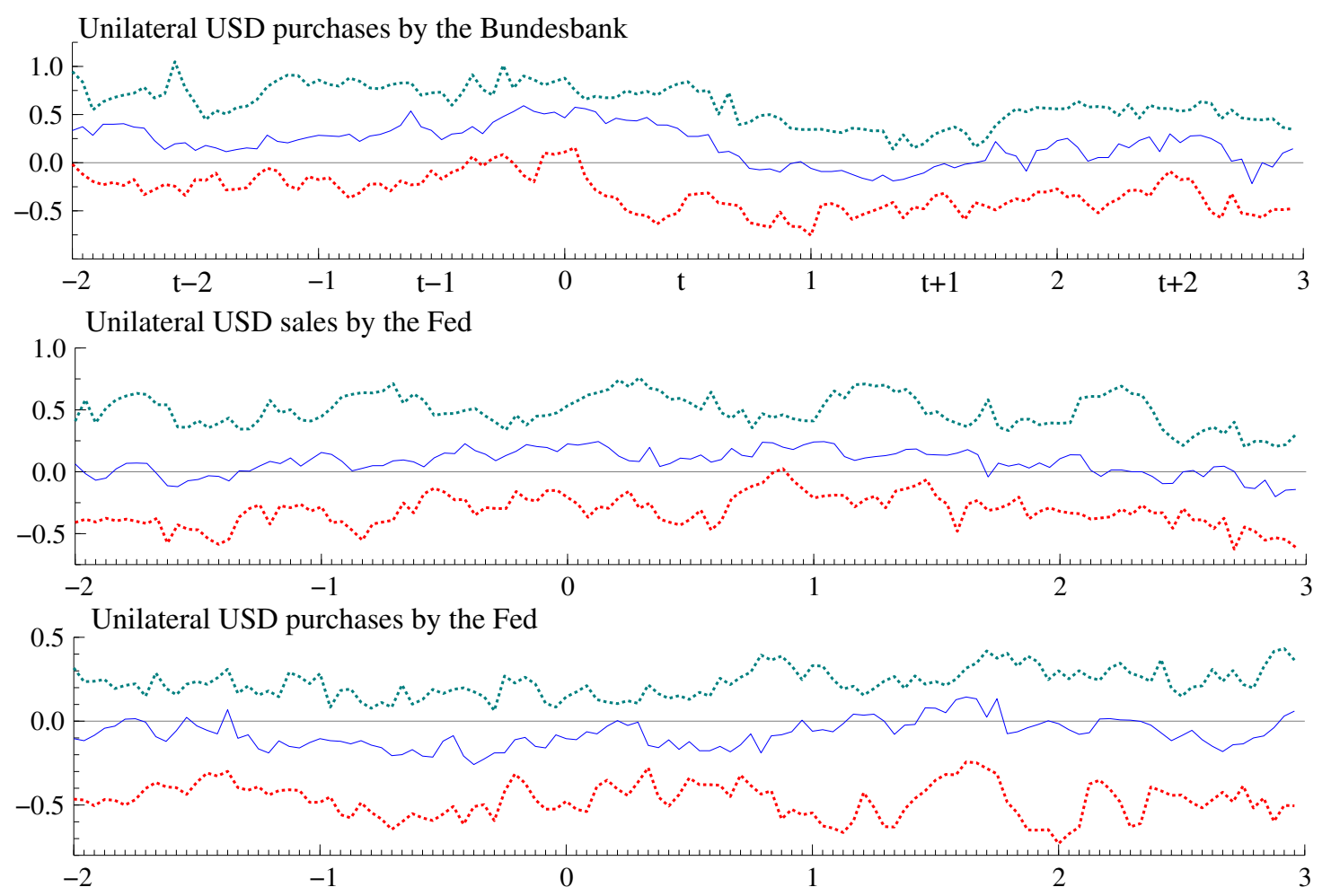

Figure 1: Boxplot of unilateral interventions in terms of daily realized DEM/USD returns 

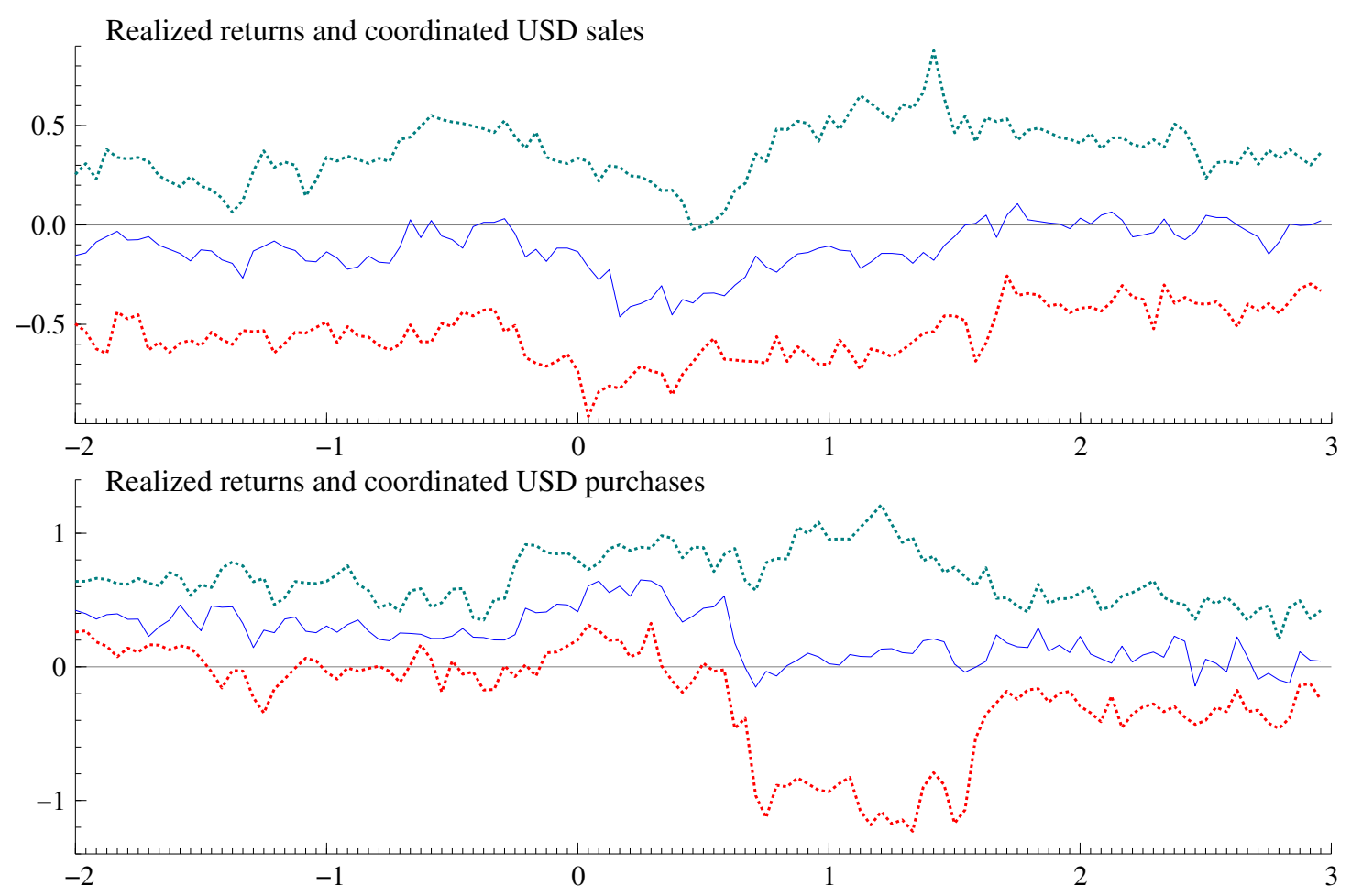

Figure 2: Boxplot of coordinated interventions in terms of daily realized DEM/USD returns 


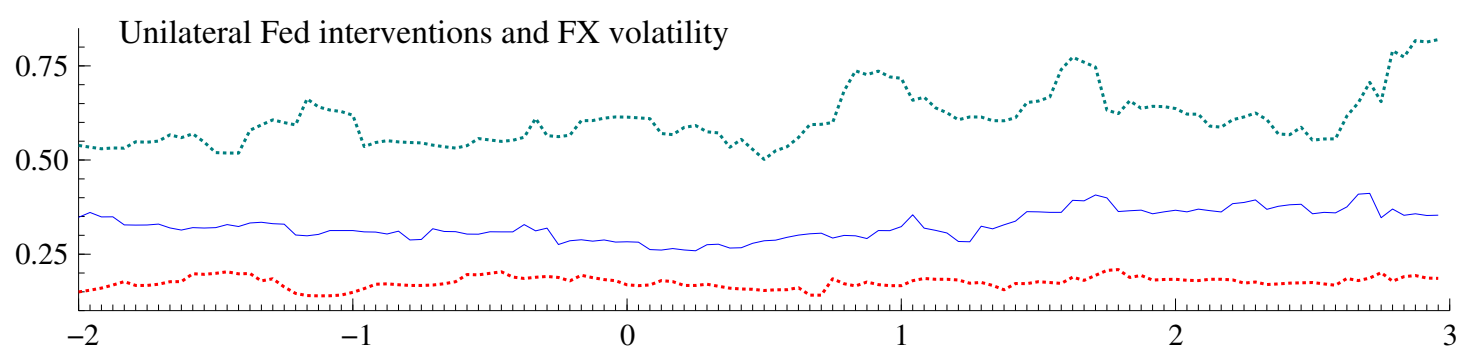

Unilateral Bundesbank interventions and FX volatility

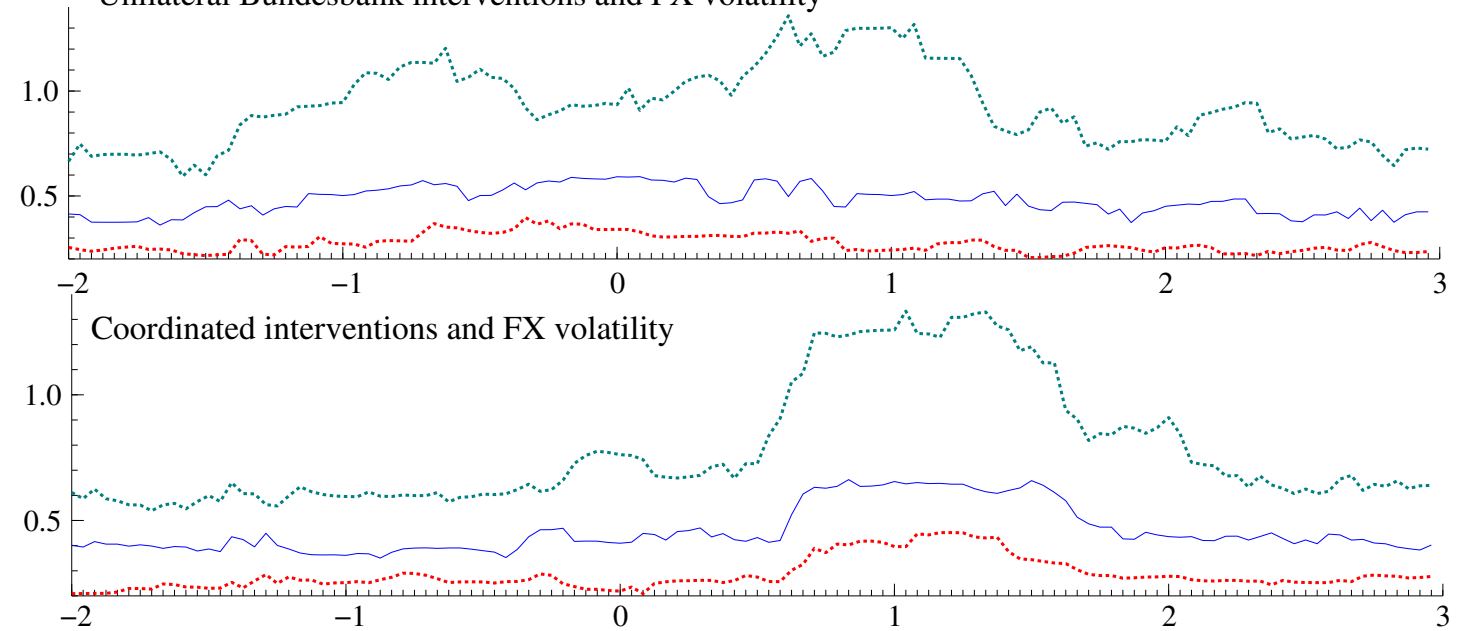

Figure 3: Boxplot of FX interventions and realized volatility 

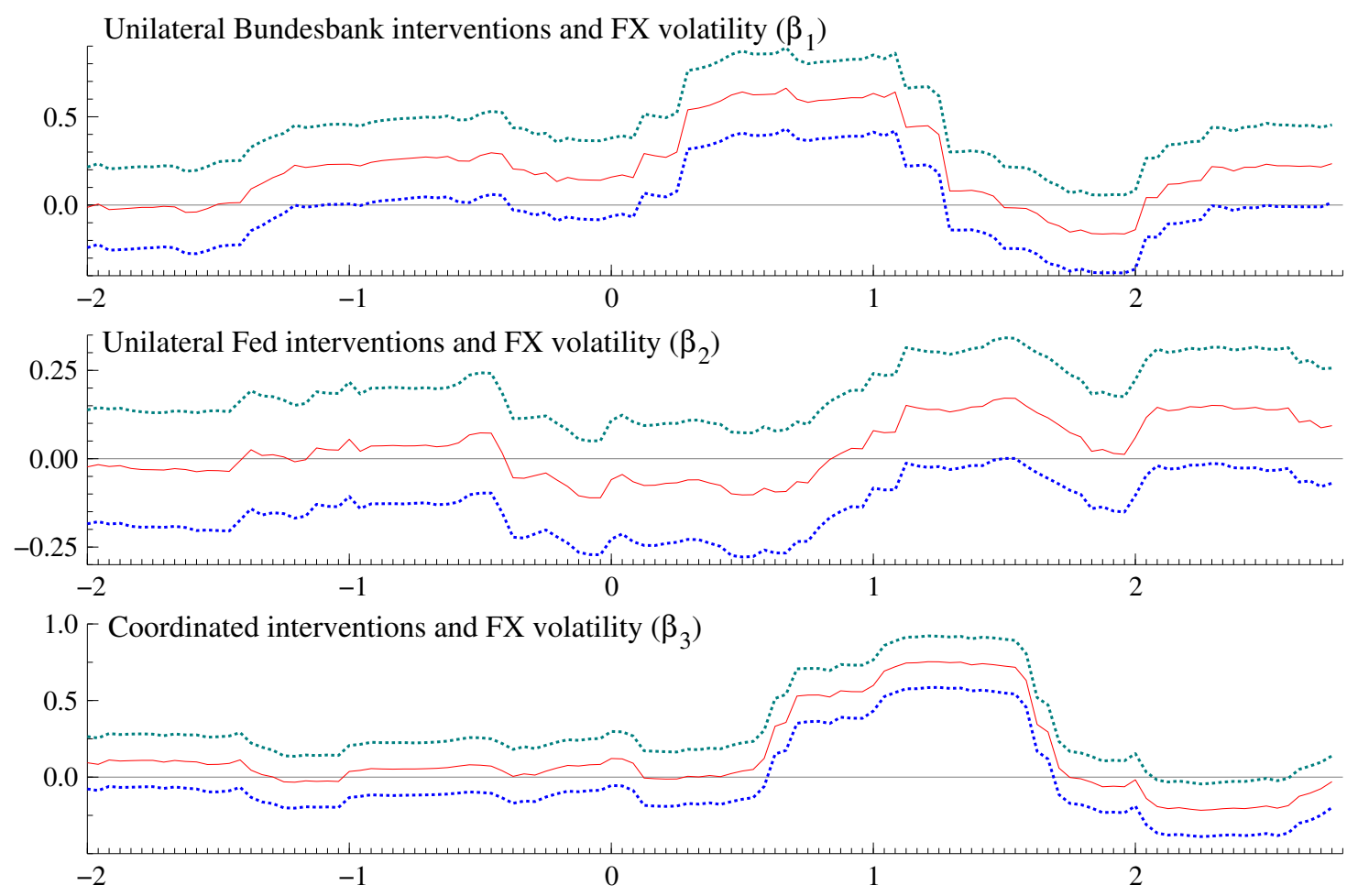

Figure 4: Rolling regressions and DEM/USD volatility 

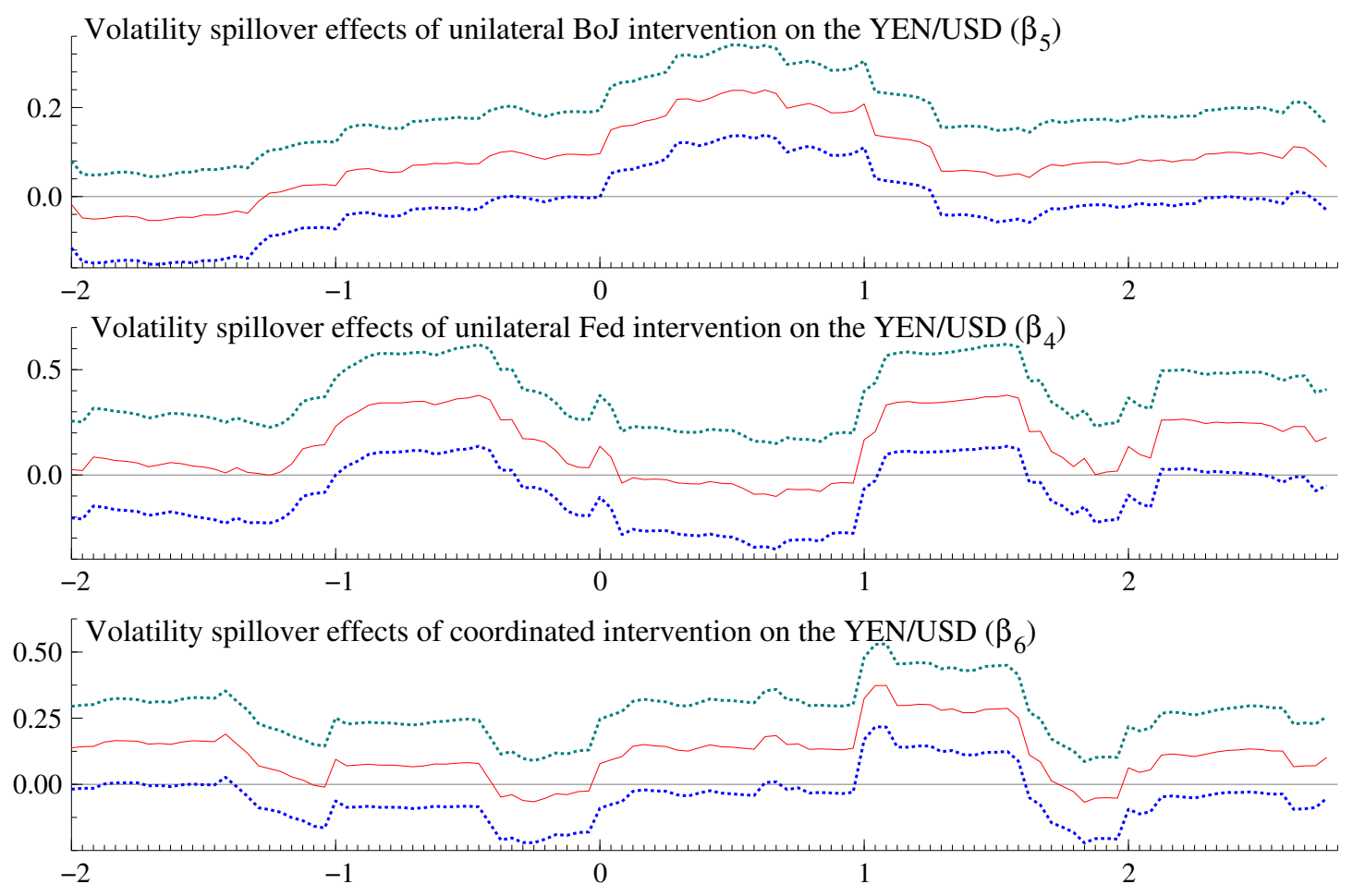

Figure 5: Rolling regressions and volatility spillover effects 

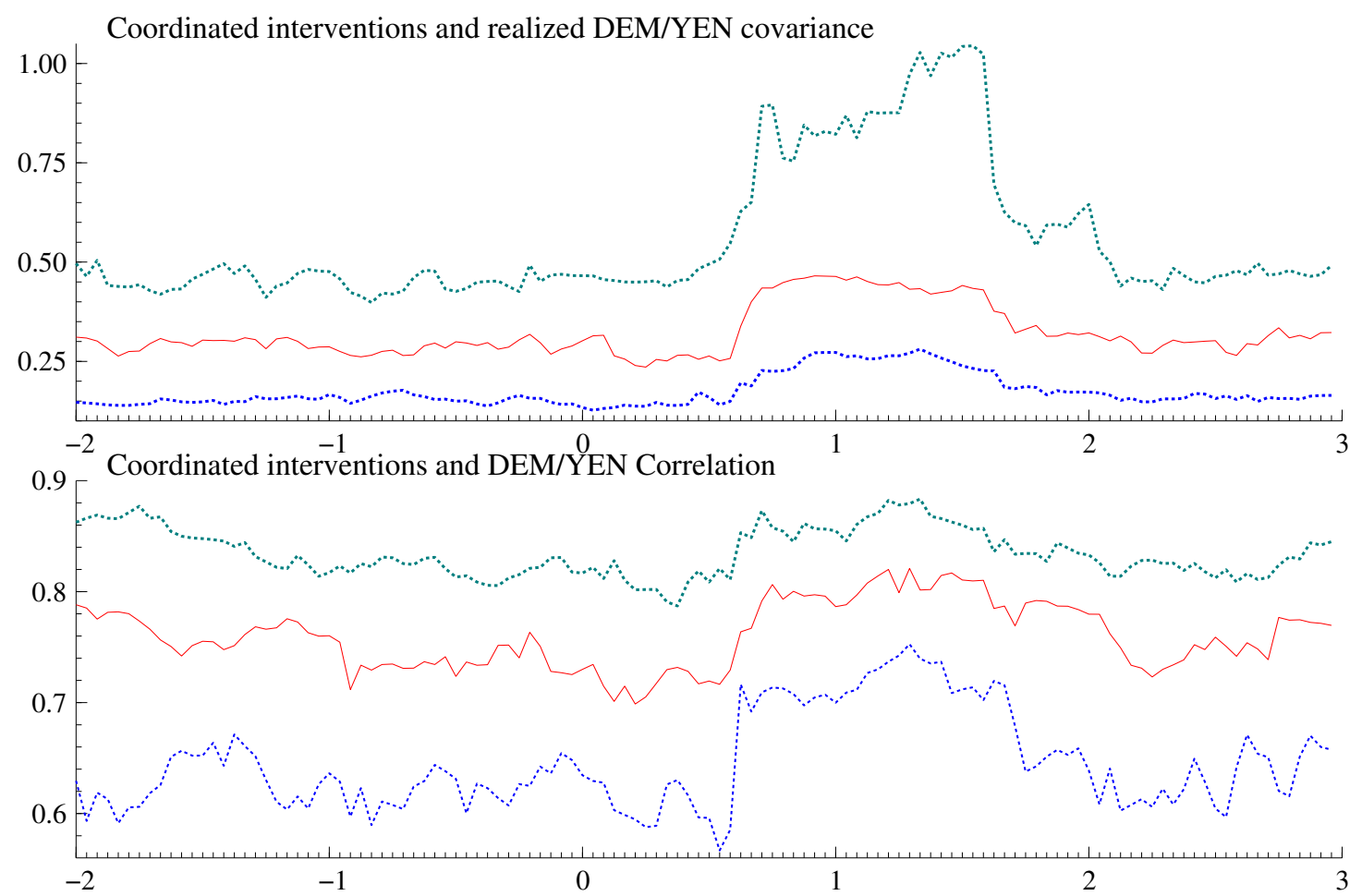

Figure 6: Boxplot of coordinated interventions on the DEM/USD and FX cross-moments 

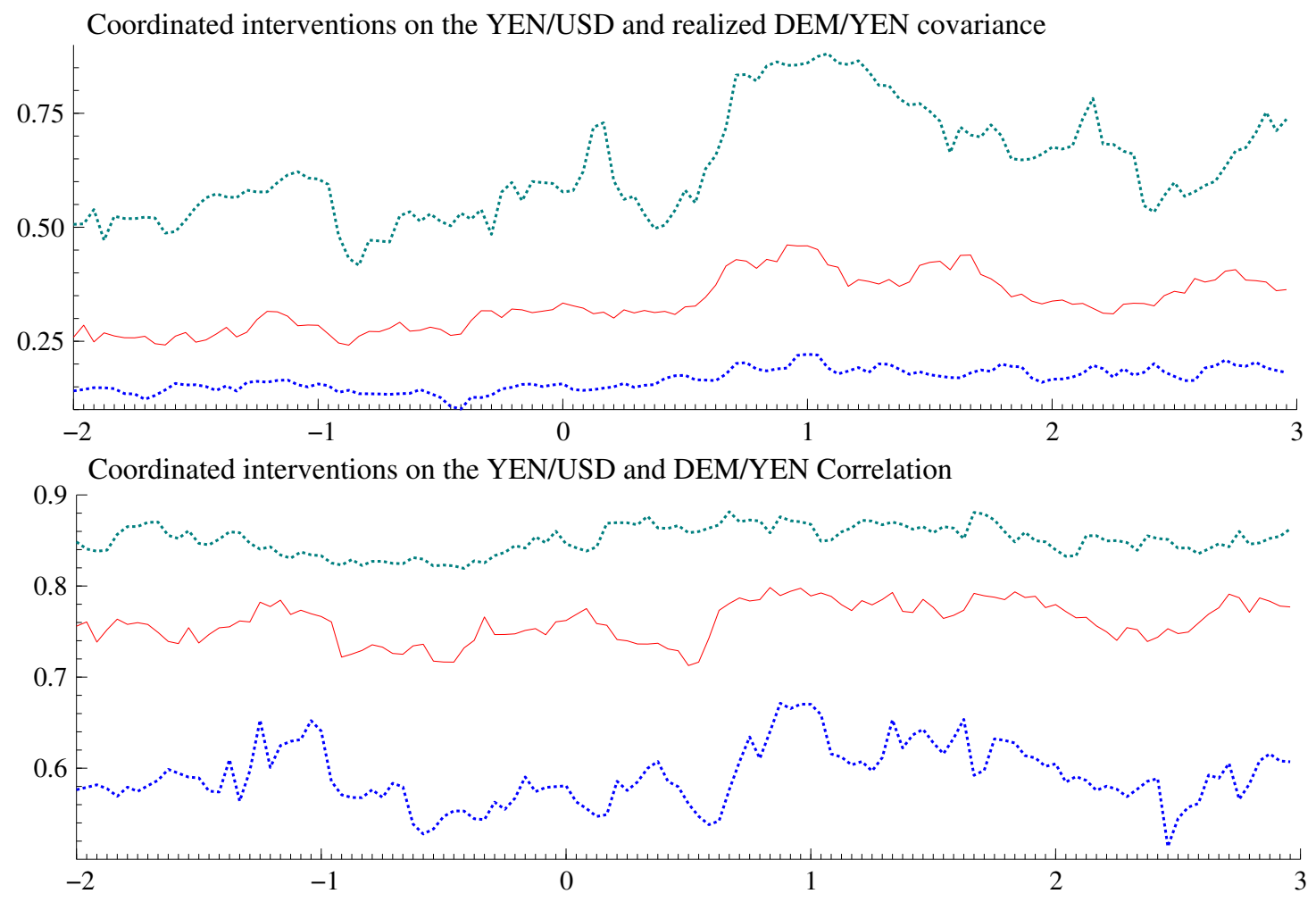

Figure 7: Boxplot of coordinated interventions on the YEN/USD and FX cross-moments 


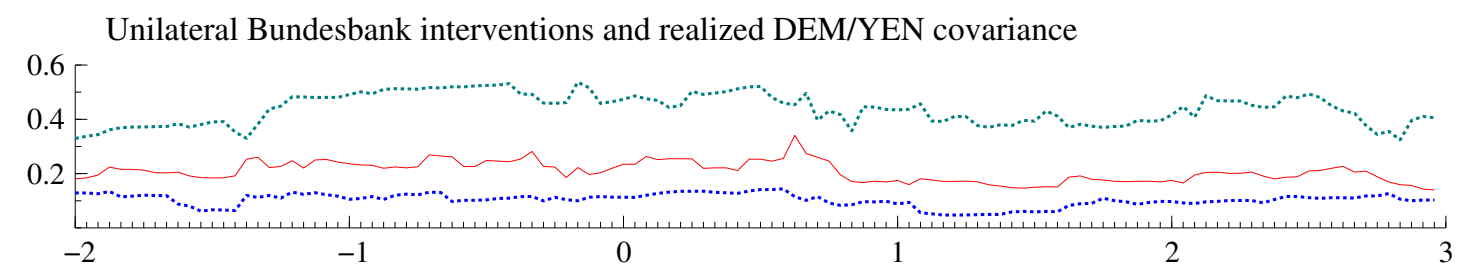

Unilateral Bundesbank interventions and realized DEM/YEN correlation
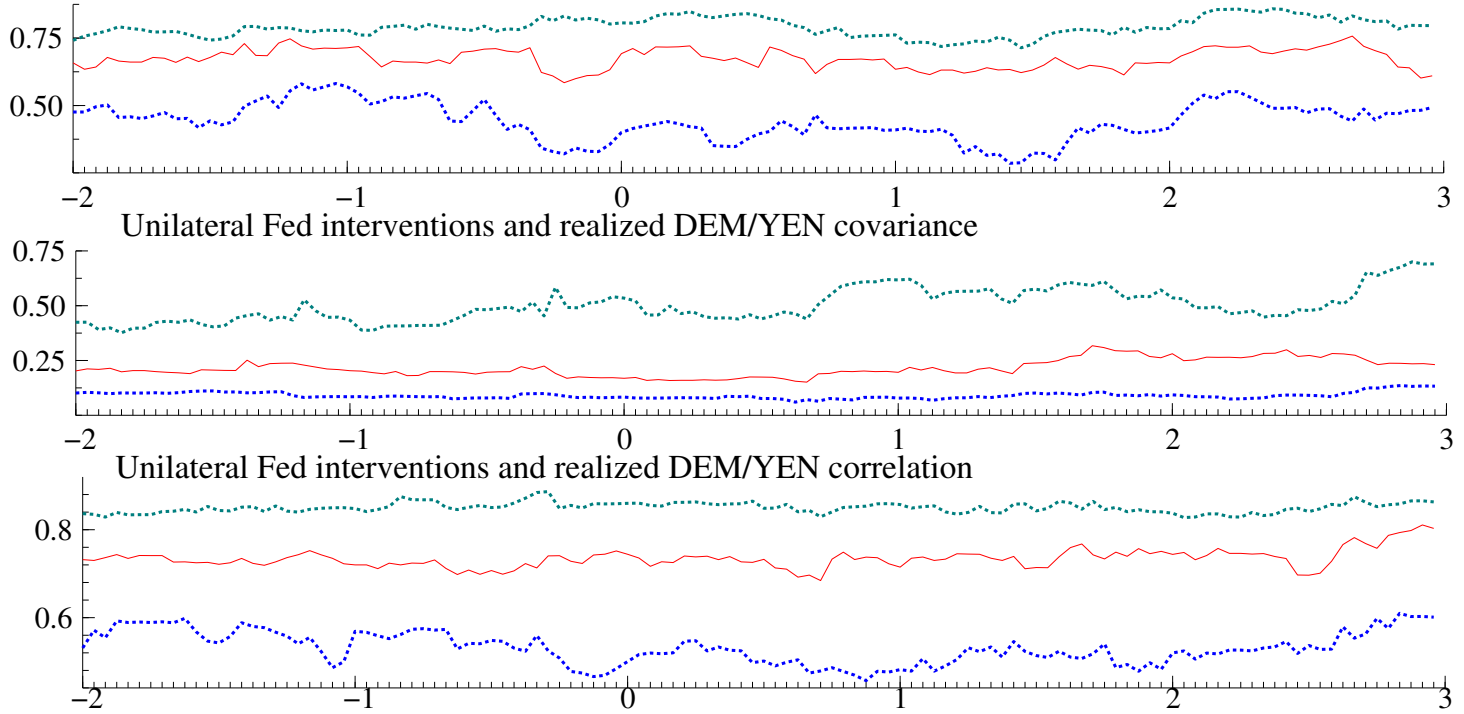

Figure 8: Boxplot of unilateral interventions on the DEM/USD and FX cross-moments 

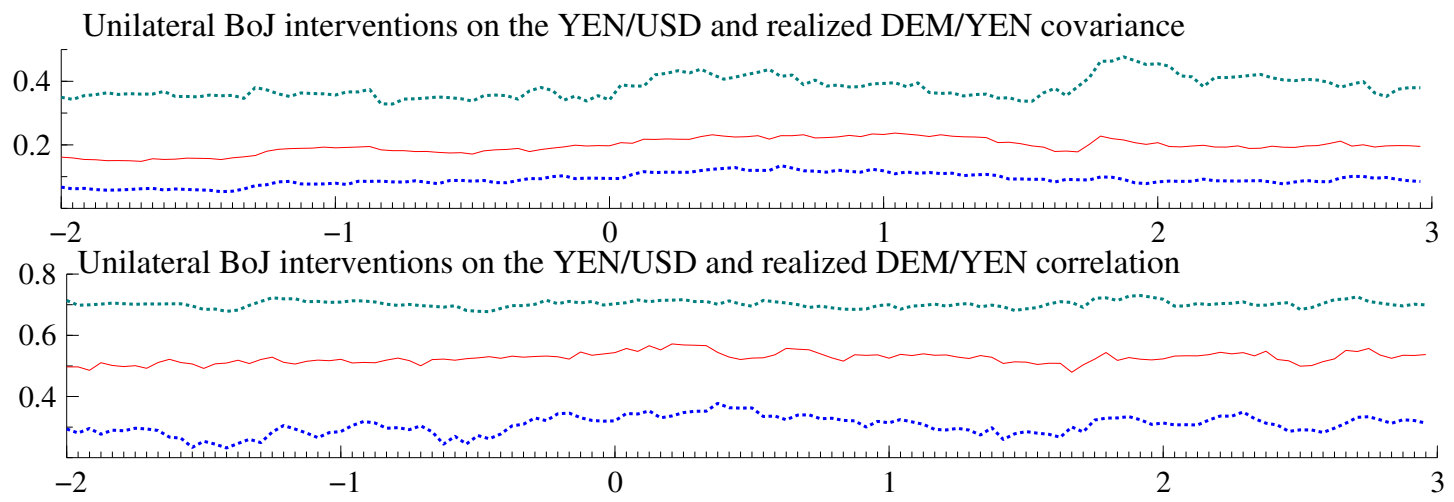

Unilateral Fed interventions on the YEN/USD and realized DEM/YEN covariance
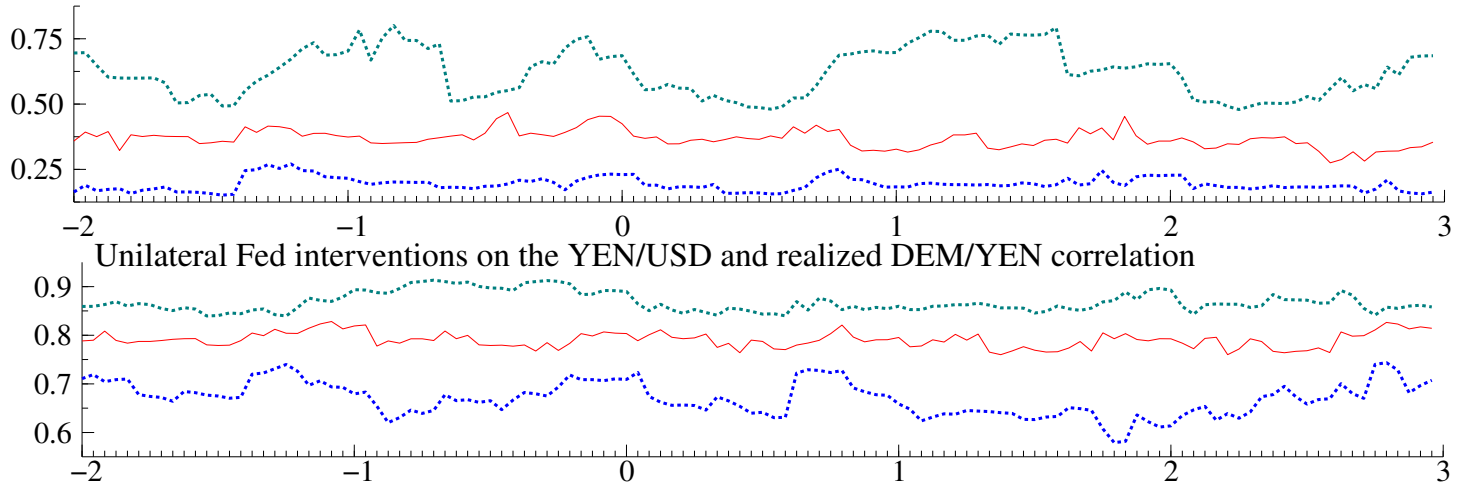

Figure 9: Boxplots of unilateral interventions on the YEN/USD and FX cross-moments 

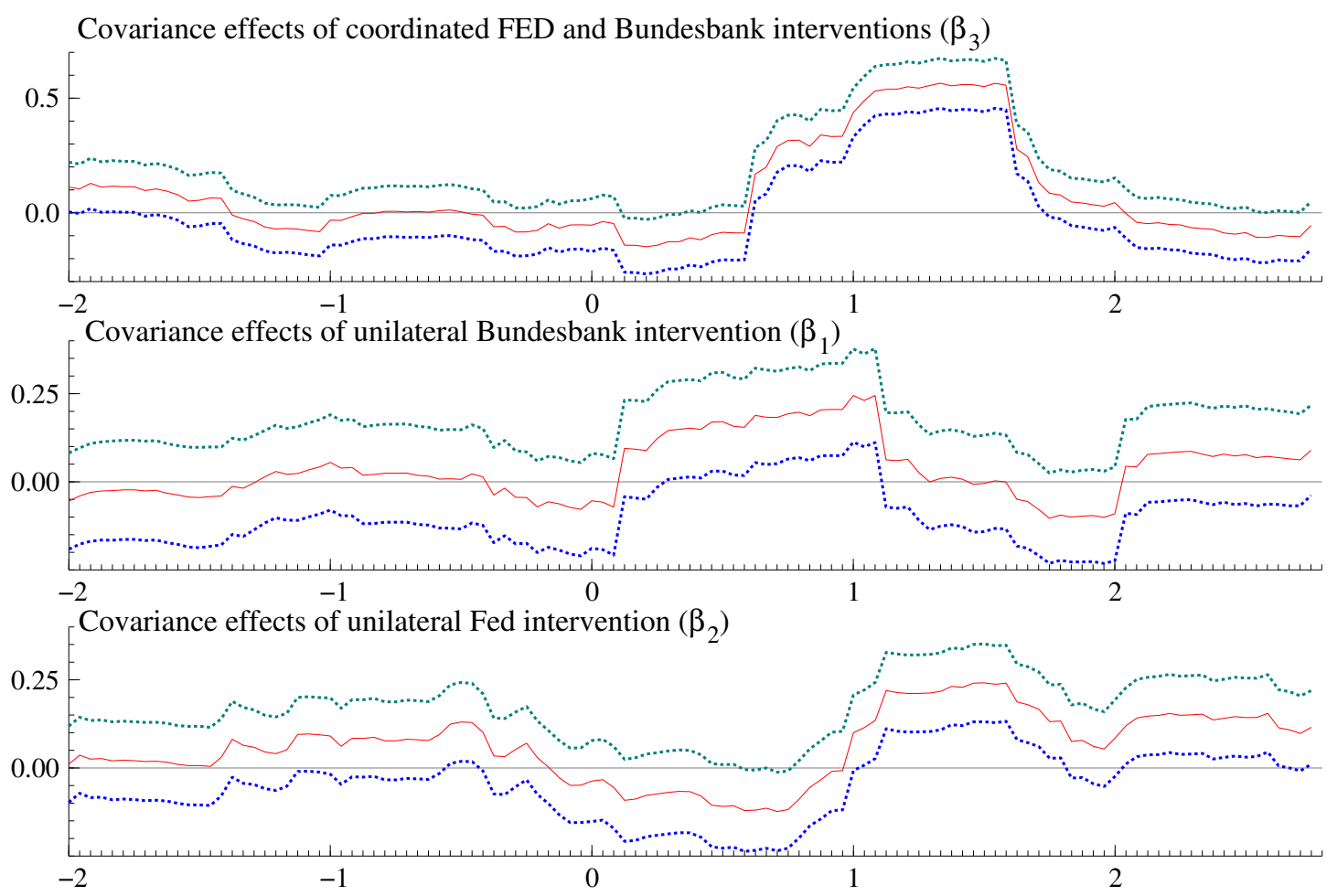

Figure 10: Rolling regressions of FX interventions on the DEM/USD on the realized cross-moments 

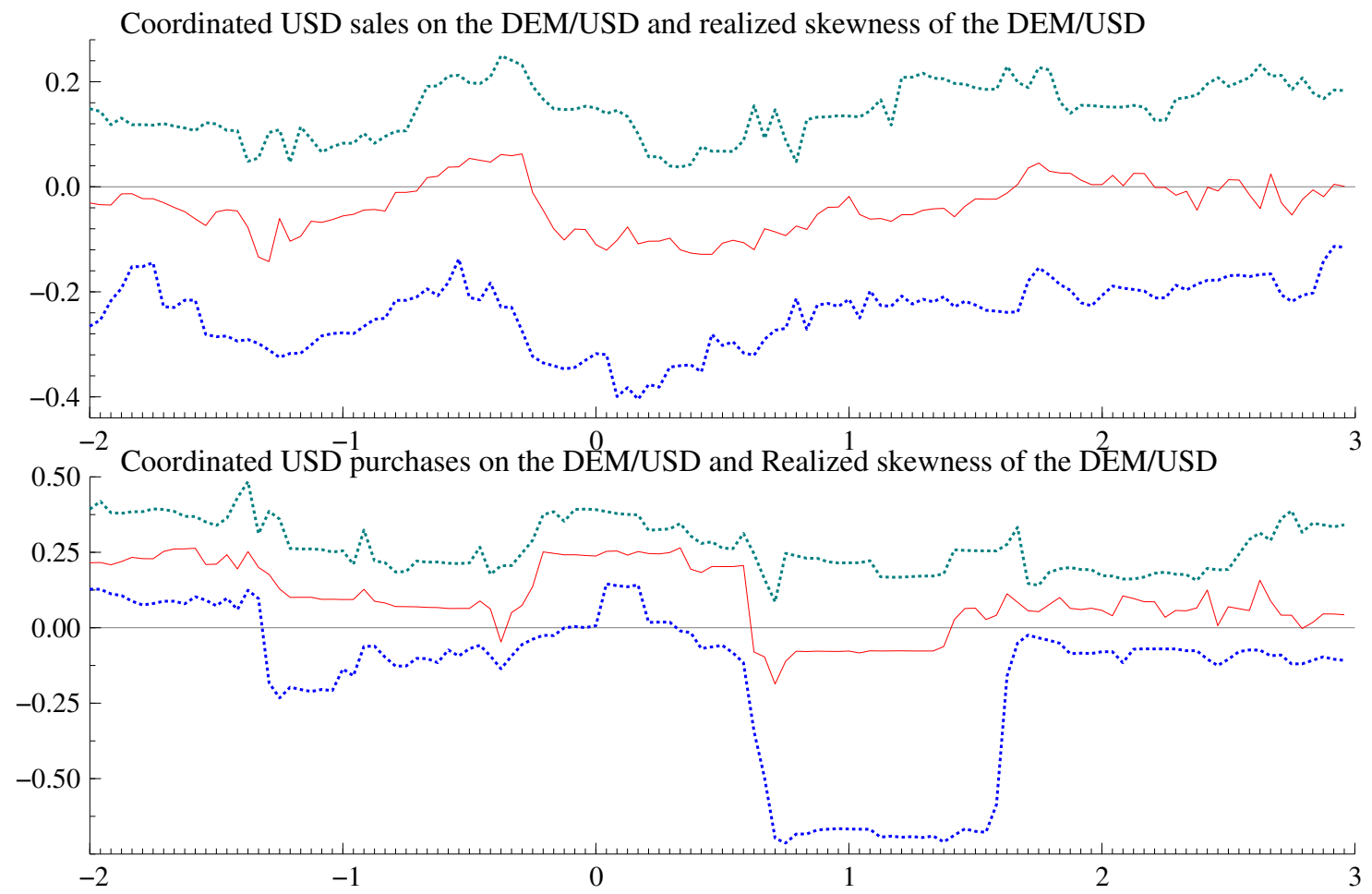

Figure 11: Boxplots of coordinated interventions and realized skewness of the DEM/USD 

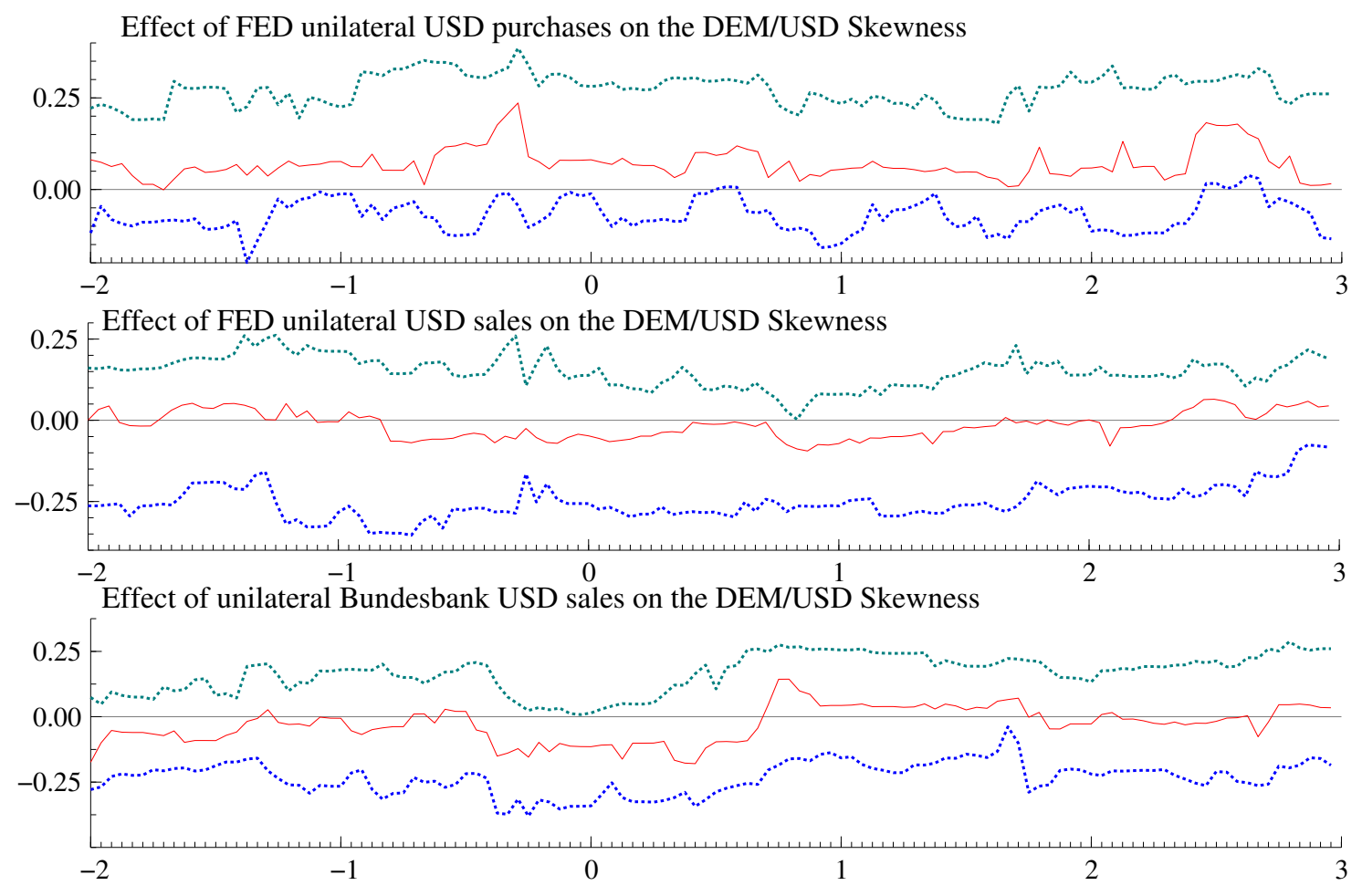

Figure 12: Boxplots of unilateral interventions and realized skewness of the DEM/USD 
Effect of coordinated USD sales on the EUR/USD Skewness $\left(\gamma_{1}\right)$
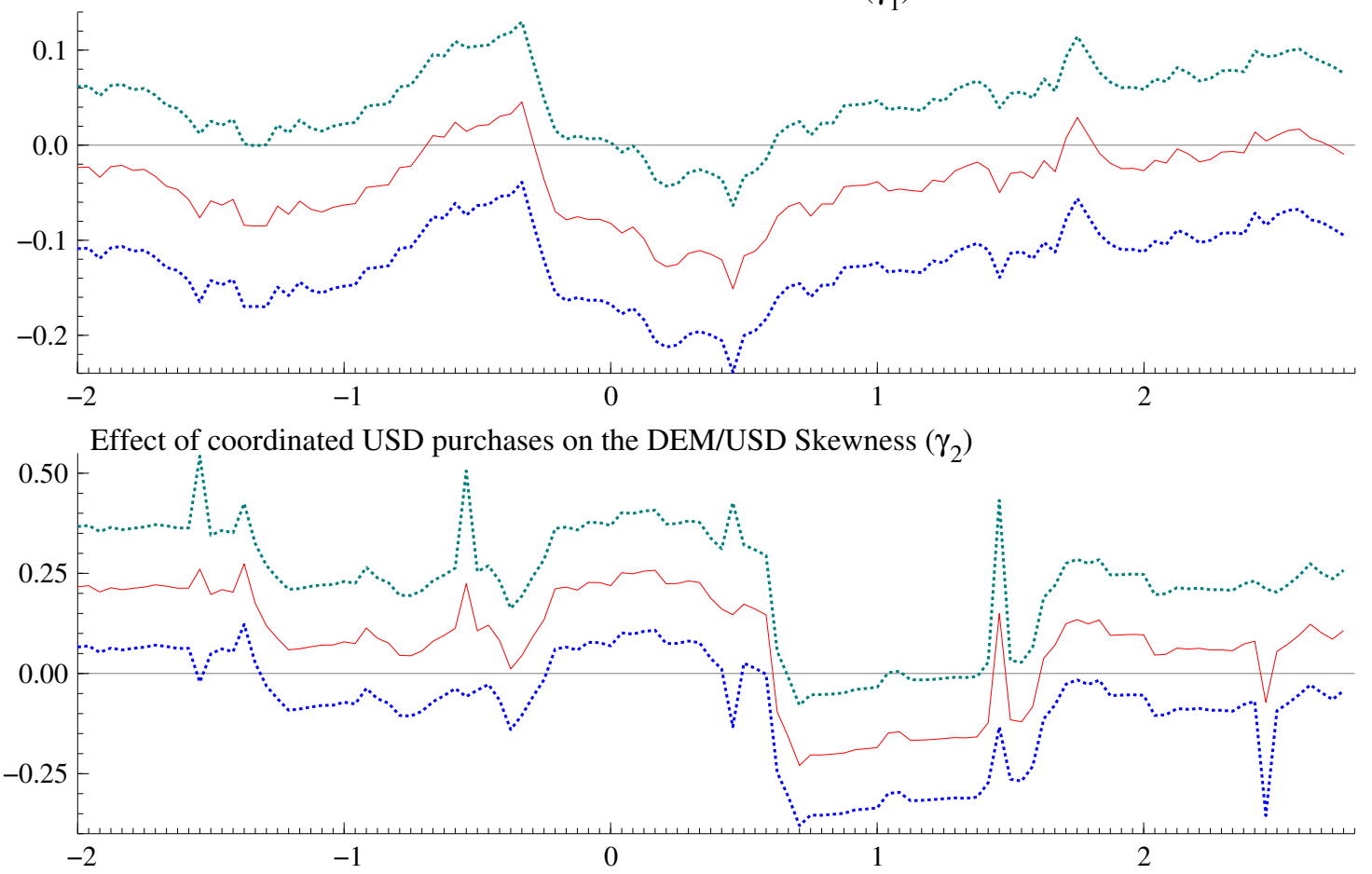

Figure 13: Rolling regressions of coordinated interventions and realized skewness of the DEM/USD 

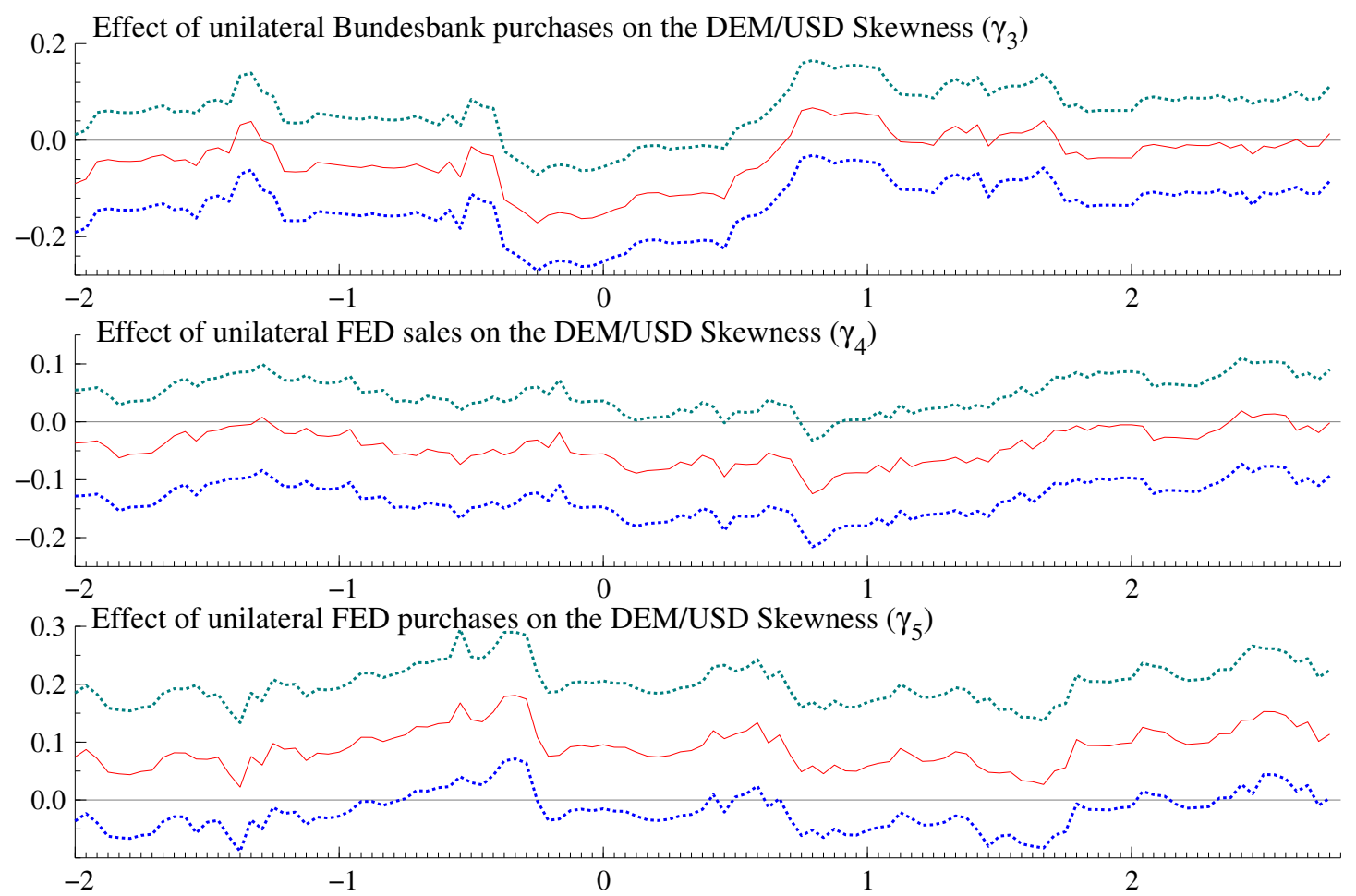

Figure 14: Rolling regressions of unilateral interventions and realized skewness of the DEM/USD 